\begin{tabular}{|c|c|c|c|c|c|}
\hline MUNIBE Antropologia-Arkeologia & $n^{\circ} 66$ & $271-290$ & DONOSTIA & 2015 & ISSN 1132-2217 • eISSN 2172-4555 \\
\hline
\end{tabular}

\title{
Tumbas rupestres en el Alto Mondego (Guarda, Portugal). Patrones de distribución, significados y construcción del paisaje rural altomedieval
}

\author{
Rock-cut tombs in Alto Mondego (Guarda, Portugal). \\ Distribution patterns, meanings and construction in the early medieval rural landscape
}

PALABRAS CLAVES: Comunidades locales medievales, territorios rurales, necrópolis, organización familiar. GAKO-HITZAK: Erdi Aroko toki-komunitateak, landatar lurraldeak, nekropolia, familia-antolaketa. KEY WORDS: Middle Age local communities, rural landscapes, necropolises, household organization.

Catarina TENTE(1)

\section{RESUMEN}

El objetivo de este artículo es presentar y discutir los datos arqueológicos sobre las tumbas excavadas en la roca obtenidos en la región del Alto Mondego. Se trata de los vestigios más abundantes y visibles de las comunidades rurales altomedievales, pero al mismo tiempo los más difíciles de comprender y explicar. A pesar de ello, el estudio de su distribución permite acercarnos a la construcción del paisaje rural entre los siglos VI y XI. Varios años de prospección y la excavación de tres yacimientos con sepulturas excavadas en la roca — Penedo dos Mouros, São Gens y Monte Aljão - permitieron la obtención de relevantes datos arqueológicos, que son los que aquí presentamos.

La categorización de sepulturas y necrópolis rupestres recientemente propuesta por I. Martín Viso motivó este trabajo, dado que permitió organizar los diferentes patrones de asociación y de distribución de las sepulturas pero, sobre todo, creó una base interpretativa para los mismos. El presente artículo, más allá de la aplicación del nuevo modelo al Alto Mondego, intenta progresar en la explicación de los patrones de distribución identificados (sepulturas aisladas, agrupamientos, necrópolis desordenadas y ordenadas). De esta manera ha sido posible comprender las formas de organización social: las tres primeras reflejan una organización de base familiar, mientras que la última es derivada de un poder supralocal. Estas manifestaciones funerarias rupestres atestiguan una intención deliberada de marcar el paisaje y los territorios familiares y comunitarios (espacios productivos y de habitación) y de la apropiación simbólica y social de los paisajes rurales.

\section{LABURPENA}

Artikulu honen helburua Alto Mondego eskualdean arrokan hondeatutako hobietan lortutako datu arkeologikoak aurkeztea eta eztabaidatzea da. Goi Erdi Aroko landatar komunitateetako aztarna ugarienak eta ikusgarrienak dira, baina, aldi berean, baita ulertzeko eta azaltzeko zailenak ere. Hala eta guztiz ere, horien banaketa aztertzeak VI. eta XI. mendeen arteko landatar paisaiaren eraikuntzara gerturatzea ahalbidetu digu. Arrokan induskatutako hilobiak dituzten hiru aztarnategitan urte askoan prospekzioak eta hondeaketak egin ostean (Penedo dos Mouros, São Gens eta Monte Aljão mendia), datu arkeologiko esanguratsuak lortu dituzte eta hemen aurkezten ditugu datu horiek.

Duela gutxi I. Martín Visok proposatutako harkaitzetako nekropolien eta hobien kategorizazioak bultzatu zuen lan hau. Horri esker, hobien banaketako eta elkarketako eredu ugariak antolatu egin ahal izan ziren, baina batez ere, horietarako interpretazio-oinarria sortzea ahalbidetu zuen. Eredu berria Alto Mondegora aplikatzeaz harago, artikulu honen helburua identifikatutako banaketa-ereduak azaltzeko lanean aurrera egiten saiatzea da (isolatutako hobiak, taldekatzeak, eta ordenatutako eta desordenatutako nekropoliak. Horrela, gizarte-antolaketako moduak ulertu ahal izan ditugu: lehen hirurek familia-oinarriko antolaketa islatzen dute. Azkena, aldiz, tokikoaz gaindiko boteretik eratorritakoa da. Harkaitzeko hilobi-adierazpen horiek agerian utzi dituzte familiako eta komunitateko lurraldeak (ekoizpeneko eta bizitokiko guneak) eta paisaia nahita markatzeko asmoa eta landatar paisaien jabetze sinbolikoa eta soziala.

\begin{abstract}
Rock-cut tombs are the most abundant remains of the communities that inhabited the Upper Mondego (Guarda district, Portugal) in the 6th11 th centuries. Despite being extremely difficult to analyse and study, their distribution and spatial relation with habitation contexts allow us to approach the making of this rural landscape. Several seasons of survey and excavations in three settlements in close vicinity to rock-cut tombs -Penedo dos Mouros, São Gens and Monte Aljão — permitted relevant archaeological data to be obtained.

A recent reinterpretation of the above type of necropolises by I. Martín Viso is the motto for the present paper. This new approach permitted different patterns of spatial association and distribution to be typified and interpreted. In addition to the adaptation of the mentioned model, we also attempt to move on the explanation of the identified distribution patterns (isolated, clustered, disordered and concentrated). It is thus
\end{abstract}

(1) Scholar professorship de la Fundação Calouste Gulbenkian. Instituto de Estudos Medieval. FCSH/ Universidade Nova de Lisboa, Av. de Berna, 26C, 1069-061 Lisboa (Portugal). E-mail: catarina.tente@fcsh.unl.pt 
possible to deduce the structure of these societies: the first three types of necropolises reflect local household-based forms of social organization while the latter is the outcome of established supra-local powers.

Rock-cut necropolises also testify a deliberate intention of marking the landscape in various ways, from long-lasting places for the dead to the economic, social and symbolic appropriation of a rural territory in Early Medieval times.

It is revealing that the work put in its construction is greater tan in the habitation sites, which were mostly built with perishable materials. The durability and location of tombs is a deliberate action. Even if we are unable to understand all its meanings, tombs can not be dissociated of the anthropization and appropriation of rural and forested spaces. Tombs, were, at the same time, enduring and legitimating landmarks with their own meaning to the buried people. The presence of tombs with the ancestors and family members is recognized as imbued of a legitimating role of the exploitation and/or possession of a given territory.

The distribution of rock-cut tombs in the Upper Mondego shoes an image of a fragmented space, testimony of local communities with households as the nuclear basis of the society. It is not possible to ensure if this fact is reflected in a scattered rural settlement; it is, however, sure that these tombs marked the forested and rural spaces that were exploited. Only the Church would be able to breakdown the Early Medieval funerary manifestations by establishing a parochial system associated to resettlement processes and administrative social and economic reforms from the 12th century onwards.

\section{1.- INTRODUCCIÓN}

En este trabajo presentamos los datos obtenidos desde la arqueología de los espacios funerarios rupestres en la región del Alto Mondego, en el centro de Portugal. Los trabajos de prospección arqueológica realizados, así como la relocalización de los yacimientos mencionados en la bibliografía permitieron la identificación de un total de 106 yacimientos con sepulturas excavadas en la roca que constituyen la base de este estudio. Los sitios con este tipo de enterramiento tienen varios patrones de localización geográfica, las sepulturas presentan tipologías diversas y también son diferentes la organización y la distribución de las sepulturas en cada yacimiento. Lo que tienen en común es que se trata de estructuras funerarias construidas en una base pétrea, duradera, y que marcan el espacio rural medieval. Las sepulturas excavadas en la roca son uno de los vestigios materiales medievales más abundantes en toda la región del centro de Portugal, pero al mismo tiempo son uno de los testimonios más difíciles de abordar e interpretar por tratarse, la mayoría de ellas, de agujeros sin ajuar ni restos óseos.

Analizar su localización, definir los patrones de organización de las necrópolis y buscar relaciones con vestigios de hábitats o espacios productivos coetáneos son la única forma de afrontar su estudio. En este artículo se pretende realizar un análisis de conjunto de los yacimientos conocidos en el Alto Mondego, discutiendo algunos casos concretos de los que se dispone más información arqueológica, con el objetivo de encontrar patrones y comprender el significado de estas construcciones funerarias en la organización del paisaje rural medieval.

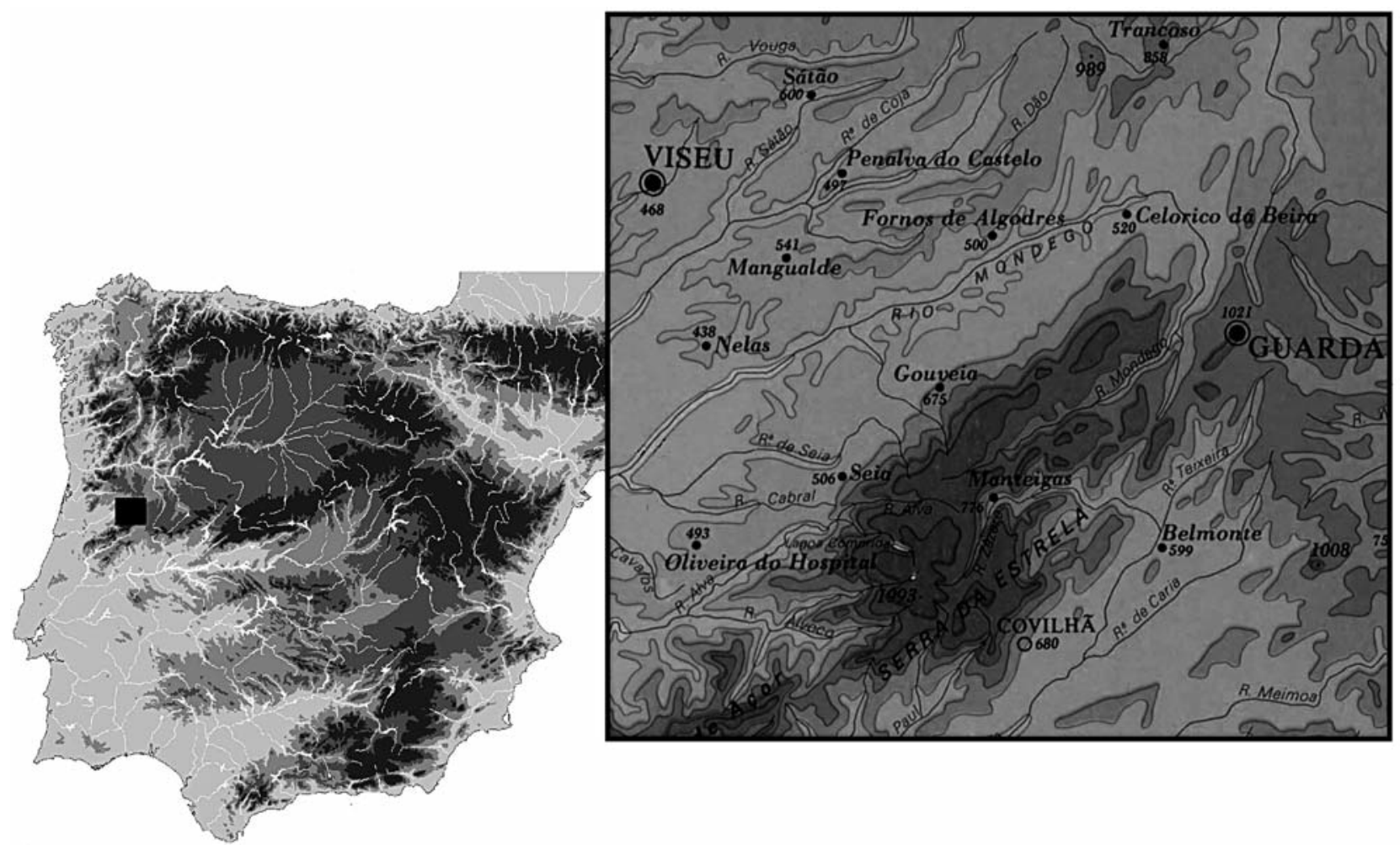

Fig. 1. Localización del área de estudio / Location of study area. 
Han sido varios los trabajos publicados en los últimos años centrados en el mundo funerario rupestre altomedieval en la Península Ibérica. En ellos se han abordado los modelos observables en la distribución geográfica de las sepulturas pero, sobre todo, han intentado explicar el significado que estos monumentos funerarios pueden tener para la comprensión de las sociedades que los construyeron y utilizaron. El mencionado proyecto dirigido por I. Martín Viso, y del que forma parte la autora, permitió realizar el estudio de varios casos, abriendo de nuevo el debate en torno a este tipo de evidencias. Martín Viso ha publicado varios trabajos en los que aborda el significado de estas sepulturas y en los que enfatiza su importancia para el estudio de las comunidades locales (2011, 2012a, 2012b, 2014; Martín Viso y Blanco-González, e.p.). Pero fue sobre todo el artículo publicado en la revista Zephyrus (Martín Viso, 2012a) el que suscitó la redacción del presente trabajo, en la medida en que propone un nuevo acercamiento y caracterización de este tipo de sitios.

Hasta 2007 publicamos varios artículos acerca de las sepulturas excavadas en la roca (Tente y Martins, 1994; Tente y Lourenço, 1998; Tente, 2000) y nos centramos en este tema, especialmente, debido a la elaboración de nuestra Tese de Mestrado, enfocada en la vertiente noroeste de la Serra da Estrela en época medieval (Tente, 2007). En todos estos trabajos se optó por la clasificación de los yacimientos arqueológicos con sepulturas excavadas en la roca en tres grupos: yacimientos con sepulturas aisladas, yacimientos con conjuntos de 2 o 3 tumbas, y necrópolis, (más de 4). Este modelo estaba profundamente influido por el trabajo de M. Barroca, llevado a cabo en 1987 y parcialmente publicado no hace mucho (20102011). Se trataba de un modelo funcional en términos de análisis, pero no profundizaba en la cuestión explicativa, vinculando de manera genérica la dispersión de las sepulturas con un poblamiento también disperso. Este trabajo suponía, en cualquier caso, un paso adelante en la manera de abordar arqueológicamente la ocupación del mundo rural altomedieval dado que presuponía, fundamentalmente, una relación entre el espacio de los muertos y el espacio de los vivos. El mismo modelo de clasificación, en buena medida fundamentado en el propuesto por Bolós y Pagés en 1982, fue aplicado en otros trabajos desarrollados en Portugal sobre sepulturas excavadas en la roca, especialmente en el área entre el Duero y el Mondego (Lopes, 2002; Lourenço, 2007; Marques, 2000; Tente e Lourenço, 1998; Tente, 2000 e 2007; Valera, 1990; Vieira, 2004, 2006).

Iñaki Martín Viso, en el artículo señalado, propone un nuevo modelo de clasificación. En una primera categoría incluye aquellos sitios con sepulturas aisladas o pequeños grupos de hasta nueve sepulturas que se organizan de forma dispersa; la segunda categoría comprende aquellos conjuntos que tienen más de diez sepulturas, que se distribuyen en el espacio de forma aparentemente aleatoria, pudiendo incluir sepulturas aisladas o grupos familiares (necrópolis desordenadas); por último, la tercera categoría incluiría las necrópolis de sepulturas alineadas y agrupadas (Martín Viso, 2012a: 170-172). La principal ven- taja de este nuevo modelo se encuentra en la definición de la correlación entre la forma de organización en la disposición de los sepulcros y la propia forma de organización de las sociedades que las construyen y usan. Además, permite valorar la localización de los sepulcros y su relación con la estructuración del paisaje rural, funcionando principalmente como marcos sociales de apropiación territorial. Por último, es importante señalar que este modelo supera, por fin, las cuestiones estrictamente vinculadas a la tipología de los sepulcros y su posible cronología, cuestión que dominaba (y aún hoy sigue presente) el debate sobre las necrópolis rupestres en la Península Ibérica desde los trabajos de Alberto del Castillo.

En el presente trabajo abordamos los vestigios funerarios rupestres hasta ahora conocidos en la región del Alto Mondego (figura 1) a partir del modelo propuesto por Martín Viso (2012a), pero introduciendo algunas variantes en la organización de los datos. Así, los 106 sitios con sepulturas utilizados como base para nuestro análisis, se distribuyen en cuatro categorías: sepulturas aisladas (constituidos por solo un ejemplar de estructura funeraria); los grupos de 2 a 9 sepulturas (pequeñas necrópolis con sepulturas dispersas); necrópolis desordenadas (conjuntos funerarios dispersos que contienen 10 o más sepulturas) y, por último, necrópolis ordenadas. Para cada una de las categorías se ofrece una visión general de los yacimientos que en ellas se integran, y se presentan uno o dos casos concretos en los que los datos arqueológicos disponibles permiten una reflexión más profunda sobre su significado y su posible cronología. Para finalizar, realizaremos una reflexión acerca de las posibilidades de aplicar este modelo de clasificación para comprender el fenómeno funerario y cómo éste se relaciona con la apropiación del paisaje rural y con la organización de la sociedad.

\section{2.- EL TERRITORIO DEL ALTO MONDEGO: UN ESTUDIO DE CASO}

La Serra da Estrela conforma el extremo más occidental del Sistema Central peninsular, configurando una cordillera de carácter granítico que alcanza los 1993 m s.n.m., siendo la máxima elevación del territorio continental portugués. La mayor cuenca fluvial la aporta el curso alto del río Mondego que, desde su nacimiento, describe una curva rodeando la Sierra por el norte y el oeste. La alta diversidad climática que caracteriza a la región se debe a la relativa cercanía del océano Atlántico, al oeste, y a la Meseta Central española, al este. La vegetación de la Serra da Estrela está condicionada por estos factores, pero también por la propia altitud, dividiéndose en tres zonas diferentes: basal (hasta los 800-900 m s.n.m.), de clara influencia mediterránea y profundamente alterada por la actividad humana; la zona media (entre 800-900 m s.n.m. y los 1300-1600 m s.n.m.), caracterizada por la decadencia del bosque de robles, debido a los incendios y al pastoreo de ovejas y cabras; y la zona superior (por encima de los 1300-1600 m s.n.m.), donde se extiende el bosque de enebros, tras la actividad humana que des- 
truyó la cobertura local post-Würmiense formada por pinos y abedules (Silva, Teles, 1999).

En el aspecto geológico, la región se caracteriza por la presencia de granitos y pizarras, a menudo apenas cubiertos por un delgado suelo ácido. Este hecho supone una limitación importante para la preservación de materiales orgánicos, como huesos humanos o de animales. Debido a la deforestación de origen antrópico y a la erosión de los suelos derivada de ella -un hecho documentado en la región desde el Neolítico-, la tierra fértil se encuentra fundamentalmente en las zonas más bajas, en los piedemontes y en los valles fluviales. Los trabajos de prospección en la región permitieron la identificación de 136 yacimientos arqueológicos, cuya cronología oscila entre los siglos VI y XII d.C. Se registraron sepulturas excavadas en la roca en 106 de ellos, lo que representa el 80 $\%$ de los yacimientos de esta cronología inventariados hasta el momento (figura 2). En total se conocen más de 475 sepulturas excavadas en la roca.

Tal y como hemos indicado anteriormente, el análisis de los 106 yacimientos con sepulturas rupestres se ha realizado en base a una categorización que combina el número de sepulcros con su forma de organización y dispersión sobre el terreno. A partir de estos datos se presentan los cuatro grupos: sepulturas aisladas, grupos entre 2 y 9 sepulturas; necrópolis desordenadas y necrópolis ordenadas.
En todos los casos identificados se ha realizado una prospección intensiva dirigida por la autora de este trabajo, con el propósito de identificar el número máximo de tumbas y de ponerlas en relación con otros vestigios arqueológicos. De otro lado, sólo se han podido realizar excavaciones arqueológicas en los casos de Penedo dos Mouros, S. Gens y Monte Aljão, siendo en este último sitio donde se han identificado tumbas bajo el actual nivel de suelo.

\subsection{Sepulturas aisladas}

Las sepulturas aisladas, es decir, aquellas que aparentemente no se asocian espacialmente con ningún otro sepulcro, representan el $36 \%$ del total de los sitios en los que se documenta la presencia de este tipo de enterramientos. Para el total de sepulturas manejado en el presente trabajo, las aisladas representan el $8 \%$, con 38 ejemplares. La mayoría de ellas son antropomorfas (62\%), habiéndose identificado también algunos ejemplos no antropomorfos (8\%), siendo el resto de tipología indeterminada (30\%).

En lo que respecta a su localización geográfica, las sepulturas aisladas se identifican en zonas de valle, en media ladera, cerca de cursos de agua, en el centro de prados o incluso en los altiplanos de la sierra, a más de $1000 \mathrm{~m}$ de altitud. Por lo tanto, parece que no se puede establecer un patrón de localización geomorfológica. Las

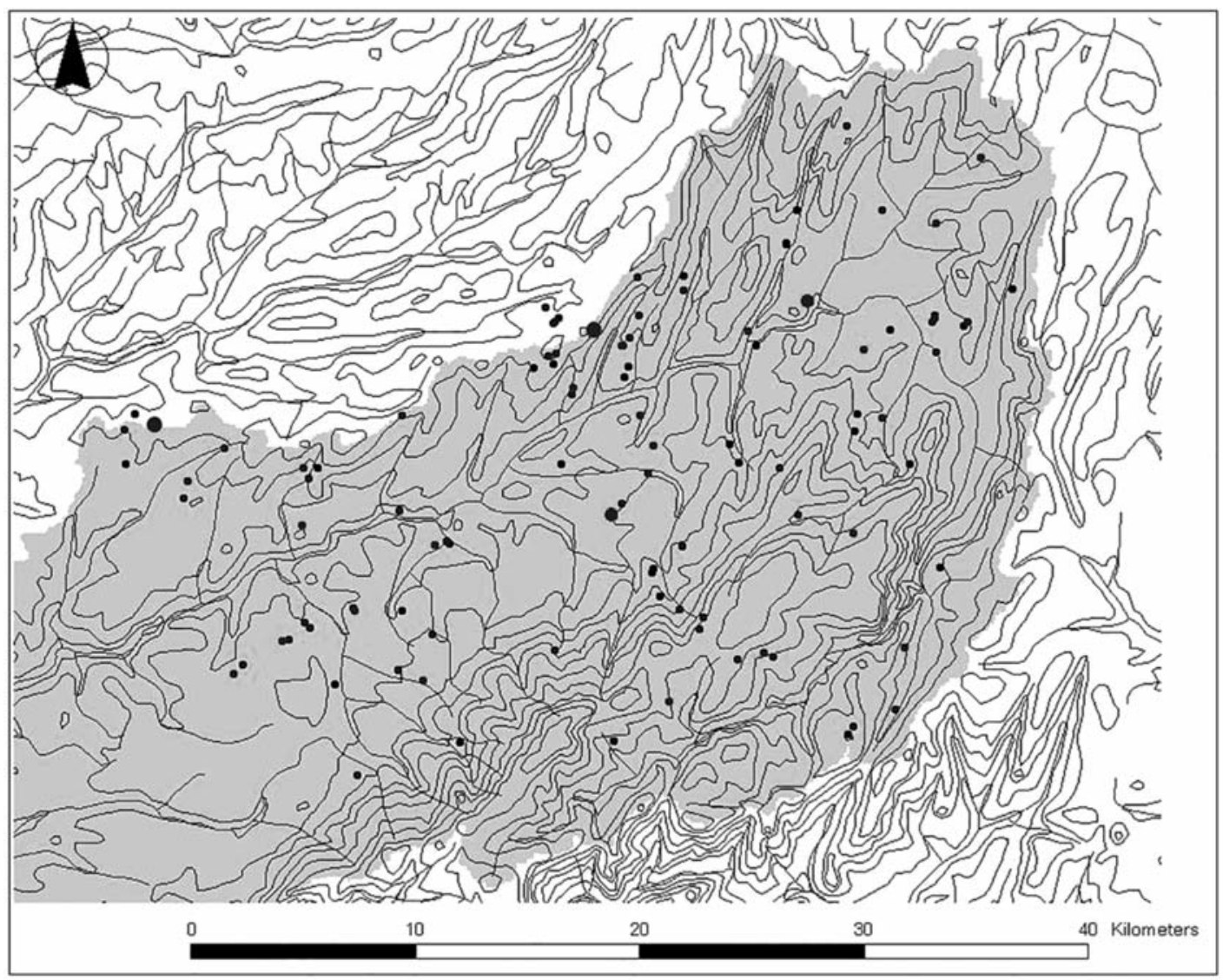

Fig. 2. Mapa de la cuenca hidrográfica del Alto Mondego, con la localización de todos los yacimientos con sepulturas tenidos en cuenta en este estudio. Los círculos de mayor tamaño indican las necrópolis con más de 20 sepulturas (según Tente, 2010: 417) / Map of Upper Mondego basin with the location of the sites with rock-cut tombs considered in this study. The major circles indicate the necropolis that have more than 20 tombs. 
orientaciones de las sepulturas también son muy variadas, aunque la tendencia dominante sea a SE, E y NE.

Aunque la mayoría son sepulturas con dimensiones que permiten ser atribuidas a la inhumación de adultos, se documenta también el caso de una sepultura infantil, excavada en pizarra y localizada en un altiplano de la sierra, en un lugar destacado en el paisaje (Casal de S. Pedro, cf. Tente, 2007: 68).

En la categoría de sepulturas aisladas hay un caso que merece una discusión más detallada, no sólo por la posición que ocupa la sepultura sino porque se encuentra en un yacimiento que fue objeto de excavaciones arqueológicas, lo que permitió la obtención de datos oportunos para la discusión de la interpretación paisajística y social de estos vestigios funerarios. Nos referimos a Penedo dos Mouros (Arcozelo da Serra, Gouveia). A pesar de que este es el único yacimiento de este grupo en el que se realizaron trabajos de excavación, los datos obtenidos mediante prospección permitieron identificar fragmentos de cerámica común y materiales de construcción en superficie en el $21 \%$ del total de los yacimientos incluidos en esta categoría.

\subsubsection{El caso particular de Penedo dos Mouros (Gouveia)}

Las campañas de excavación, realizadas por la autora, que tuvieron lugar en 1998, 2008 y 2009, permitieron la identificación de un asentamiento fortificado situado en una plataforma sobre el fértil valle del Boco. Los entalles en algunos bloques graníticos de su lado oriental soportarían una estructura de madera construida con rebollo y castaño (Queiroz y Ruas, 2001).

El control visual desde el yacimiento es bastante limitado, hecho que probablemente formara parte de la estrategia defensiva del enclave (Angelucci, Tente y Martins, 2004). La selección del valle del Boco como lugar de emplazamiento no fue aleatoria: se trata del valle más fértil de la región, y fue explotado por el grupo humano establecido en el Penedo dos Mouros. Como ejemplo podemos señalar los centenares de habas encontradas durante la excavación que bien pueden proceder de cultivos locales (Queiroz e Ruas, 2001; Van Lewarden e Queiroz, 2003).

El yacimiento fue abandonado tras un incendio datado en la segunda mitad del siglo $\mathrm{X}$, provocando la destrucción y el derrumbe de las estructuras de madera (Tente y Carvalho, 2011).

El sitio de Penedo dos Mouros tiene la llamativa particularidad de tener una sepultura excavada en la roca situada en lo alto del principal tor granítico (figura 3). Si bien no es posible afirmar que las estructuras de madera y piedra, datadas mediante radiocarbono en el siglo X, sean contemporáneas de la sepultura, la localización de la misma (por encima de la estructura lígnea) y su asociación espacial con el mayor tramo de escalones excavados en el granito, permiten relacionar de manera singular estas evidencias. La explicación más plausible es que la sepultura se construyó tras la destrucción y el abandono del asentamiento. Esta posibilidad hace más fácil comprender su localización, dado que una vez destruidas las estructuras de madera sería más sencillo elegir un espacio destacado en el que situar la sepultura. Siguiendo esta hipótesis, habría que considerar que quien excavó y utilizó esta sepultura antropomórfica vivió en una época en la que la memoria y/o la tradición oral mantendría aún viva la ocupación humana del lugar y, quizás, del hecho que provocó su destrucción y abandono. La sepultura de Penedo dos Mouros marcaría así la memoria colectiva del lugar a través de la inhumación de un individuo en especial. Cabe la posibilidad de que este personaje fuera alguien que tuviera un vínculo especial, directo o familiar, con el asentamiento. Quizá se tratara de una persona que ejerció un papel destacado en la comunidad que lo ocupó.

Por los datos disponibles hasta el momento, este modelo de sepultura única implantada de forma destacada y empleando una buena técnica de trabajo en la roca no se repite en ningún otro sitio en el Alto Mondego.
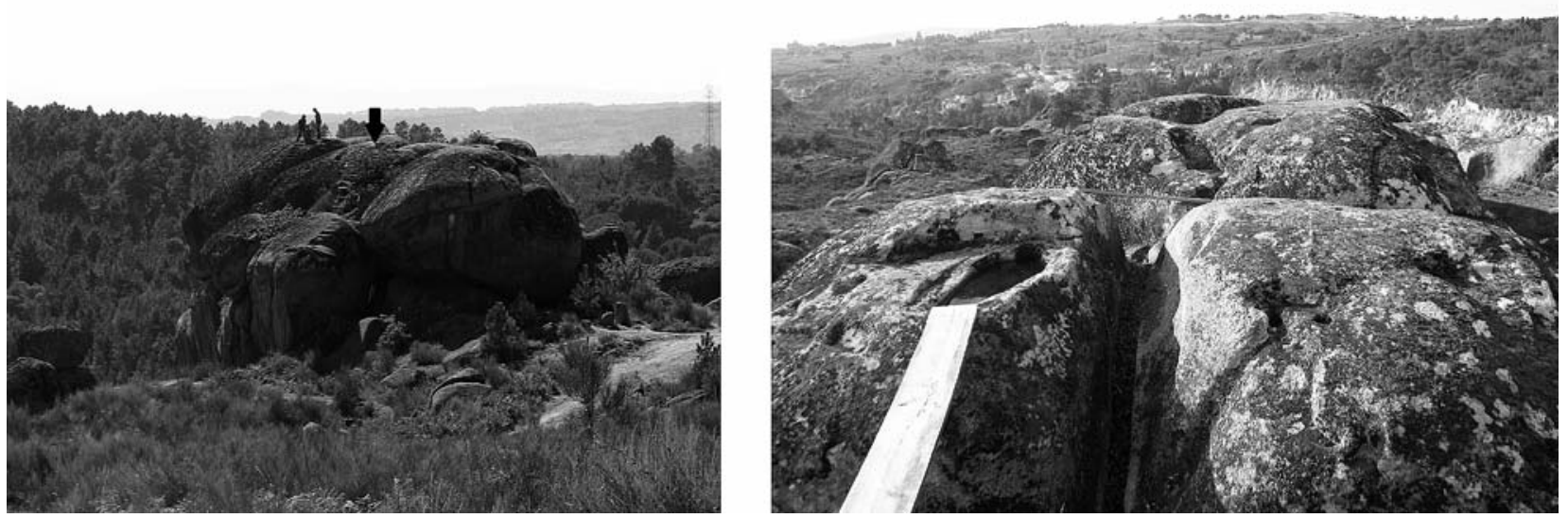

Fig. 3. El yacimiento de Penedo dos Mouros (Gouveia): señalización de la localización de la sepultura en la cima del tor granítico (flecha) y fotografía de la sepultura antropomorfa excavada en la roca / Site and tomb Penedo dos Mouros (Gouveia). The arrow indicates the location of the tomb. 


\subsection{Grupos de 2 a 9 sepulturas}

La asociación espacial de 2 a 9 sepulturas es el modelo de agrupación más habitual en el Alto Mondego, representado en el $52 \%$ de los yacimientos e incluyendo más de 214 sepulcros. De ellos, la mayoría contiene de 2 a 5 sepulturas (51 yacimientos) y sólo en 4 casos se registran de 7 a 9 sepulturas. Consideramos que deberían denominarse mejor núcleos sepulcrales que necrópolis, si entendemos éstas como los cementerios de una comunidad. Estos conjuntos tienen la singularidad de no encontrarse ordenados, tal y como definió Martín Viso (2012a), es decir, se encuentran dispersos por el territorio sin un patrón aparente.

Una vez más, la implantación geográfica de estos conjuntos no sigue ninguna regla predominante. Se encuentran en plena sierra, en laderas suaves o abruptas, en altiplanos, pero también en valles y en áreas con fácil acceso a cursos de agua. No parece que exista una pauta dominante.

Desde el punto de vista de la tipología, son mayoría los grupos cuyas sepulturas son todas antropomorfas, algo parecido a lo que sucedía en el caso de las sepulturas aisladas. La mayoría de las sepulturas excavadas en la roca en esta región son antropomorfas, y los grupos de 2 a 9 sepulturas reflejan esa preferencia formal. Sólo en dos casos encontramos una vinculación espacial entre sepulturas que no son antropomorfas, mientas que en 11 de los casos la asociación es mixta. Los grupos con sepulturas exclusivamente antropomorfas representan más de la mitad de los conjuntos estudiados en el Alto Mondego.

Durante los trabajos se identificaron sepulturas inacabadas en 6 de los 51 conjuntos identificados. También fue posible documentar la existencia de tres sepulturas infantiles. Generalmente las sepulturas que constituyen estos grupos funerarios no se encuentran concentradas. Es decir, a pesar de ser pocos sepulcros, no están alineados entre sí y, aparentemente, su posición es desordenada, obedeciendo a una lógica interna que no conseguimos recuperar. La excepción a esta regla son los conjuntos de dos sepulturas excavadas en un mismo afloramiento rocoso. En estos casos, las orientaciones de los sepulcros suelen ser similares, aunque también está documentada la situación en la que las sepulturas excavadas lado a lado fueron orientadas en sentidos opuestos, provocando que los difuntos allí inhumados quedaran afrontados (Tapada, Linhares, cf. Tente, 2007).

Este caso concreto se suma a otros siete en los que las sepulturas fueron excavadas en el mismo afloramiento. Estas asociaciones espaciales directas pueden vincular dos sepulturas atribuidas a individuos adultos, o también a un adulto y un joven o un niño. En estos casos parece evidente deducir la relación familiar entre los individuos inhumados, relación que sin embargo puede expresarse también a través de la proximidad más o menos relativa de sepulturas excavadas en afloramientos diferentes. En cualquier caso, consideramos que es precisamente esa relación familiar entre los individuos la que motiva la cons- titución de estos pequeños grupos o conjuntos sepulcrales. El argumento principal de esta hipótesis es la baja cantidad de sepulturas que conforman estos grupos, y el hecho de que normalmente se concentran en áreas relativamente limitadas, aunque no estén agrupadas y no presenten una misma orientación. Por otro lado, la correlación espacial con la presencia de restos en superficie resulta innegable en 20 de los yacimientos estudiados. Obviamente este argumento puede ser discutido, dado que los vestigios en superficie no se pueden asociar de manera inequívoca y directa con un tipo de yacimiento o con una cronología concreta. Esto resulta evidente en el caso de cerámicas comunes, indeterminadas, o con formas que presentan una dilatada utilización a lo largo del tiempo.

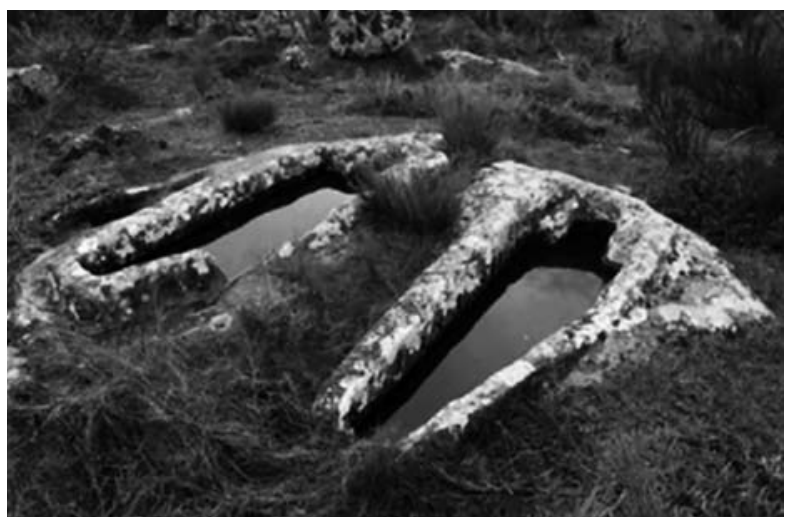

Fig. 4. Sepulturas del Casal das Pias (Gouveia), localizadas en una pequeña planicie de la sierra, a más de 1200 m de altitud. En un espacio limitado, cercano a los $250 \mathrm{~m}^{2}$, fueron excavadas cinco sepulturas de borde resaltado y orientadas a diferentes cuadrantes / Tombs from Casal das Pias (Gouveia). These are located in a small platform in the mountain $(1200 \mathrm{~m})$. In a limited space were excavated 5 tombs with different shapes and orientations.

Sin embargo, en los últimos años han sido excavados algunos yacimientos en los que existían restos cerámicos alto medievales en las inmediaciones de las sepulturas rupestres. Los resultados obtenidos hacen más verosímil la contemporaneidad de casas y sepulturas. En el caso portugués ha sido publicado recientemente (aunque con escaso desarrollo de la información aportada) la excavación del yacimiento de Monte dos Currais (Reguengos de Monsaraz, Alentejo Central), cuyos trabajos se vinculan a las medidas de minimización del impacto de la construcción del embalse de Alqueva. En este emplazamiento se habían inventariado dos sepulturas excavadas en la roca (una de adulto, otra infantil) y, junto a las mismas, fueron identificados algunos fragmentos cerámicos. La excavación arqueológica reveló una estructura doméstica de carácter rural con cinco compartimentos, de plantas rectangular y cuadrangular, situada a unos $10 \mathrm{~m}$ de distancia de las sepulturas. La cronología (s. VII) atribuida por el equipo responsable de la excavación se basa, fundamentalmente, en una placa de cinturón liriforme encontrada en unos de los compartimentos (Ferreira, 2013: 53-73). En el verano de 2014, en el ámbito del proyecto 
coordinado por Sara Prata se excavó, en el municipio de Castelo de Vide (Alto Alentejo), una estructura semejante asociada a una sepultura rupestre, con una cronología alto medieval (comunicación personal).Sólo tras el estudio detallado del registro material -actualmente en curso- se podrá precisar la cronología. En territorio español, y dentro del proyecto en el que este trabajo se incluye, podemos reseñar las intervenciones realizadas en varios sectores del yacimiento de La Genestosa (Casillas de Flores, Salamanca). A lo largo de c. 6 km se identificaron 23 sepulturas, también aisladas o organizadas en núcleos que incluyen entre 1 y 3 sepulturas que se distribuyen en un pequeño valle (Paniagua Vara, 2012). Más allá de una probable ocupación alto-imperial, se identificaron estructuras alto medievales datadas provisionalmente entre los siglos V-VI (Rubio Díez, 2011; Marín Viso y Rubio Díez, 2013 y 2014). Estas estructuras se localizan en las inmediaciones de algunas de las sepulturas, en un modelo que recuerda al identificado en el Alentejo.

En todos los casos indicados las sepulturas, aparentemente aisladas o en grupos reducidos, se sitúan en las inmediaciones de estructuras habitacionales o productivas, normalmente de pequeña dimensión y atribuibles a una unidad familiar más o menos amplia. Es decir, la elección del lugar de inhumación se relaciona de manera directa con el espacio habitado o explotado agrícolamente por un grupo reducido de individuos que comparten una misma habitación, la familia.

\subsection{Necrópolis desordenadas}

En el Alto Mondego, además de las sepulturas aisladas y de los pequeños grupos, se identificaron necrópolis que agrupan más de 10 sepulturas. Este modelo representa el 7,5\% de los yacimientos estudiados, con más de 141 sepulturas. Sin embargo la mayoría de estos grupos tiene un número reducido de sepulturas: cinco de ellos no tiene más de 14 sepulturas, y sólo uno llega a las 22 (Tapada do Anjo, cf. Valera, 1990 y Tente, 2007). La única excepción, en términos de tamaño, es São Gens (Celorico da Beira), que reúne un mínimo de 54 sepulturas.

Estas necrópolis presentan un comportamiento disperso muy parecido a los grupos descritos previamente. Las sepulturas tienden a organizarse en núcleos, es decir, se distribuyen en conjuntos que pueden ocupar el mismo afloramiento o afloramientos cercanos. Este es el único rasgo organizativo que parece deducirse, puesto que las sepulturas que conforman las necrópolis y los núcleos que los forman no están alineados entre sí, no tienen la misma orientación, y tienen tipologías diversificadas ${ }^{1}$. Uno de los ejemplos es el de la Tapada do Anjo (Vila Ruiva, Fornos de Algodres) que reúne, en un área muy extensa, 22 sepulturas de adultos e individuos infantiles y juveniles (figura 5). Éstas se organizan en tres núcleos, a las que hay que aña-

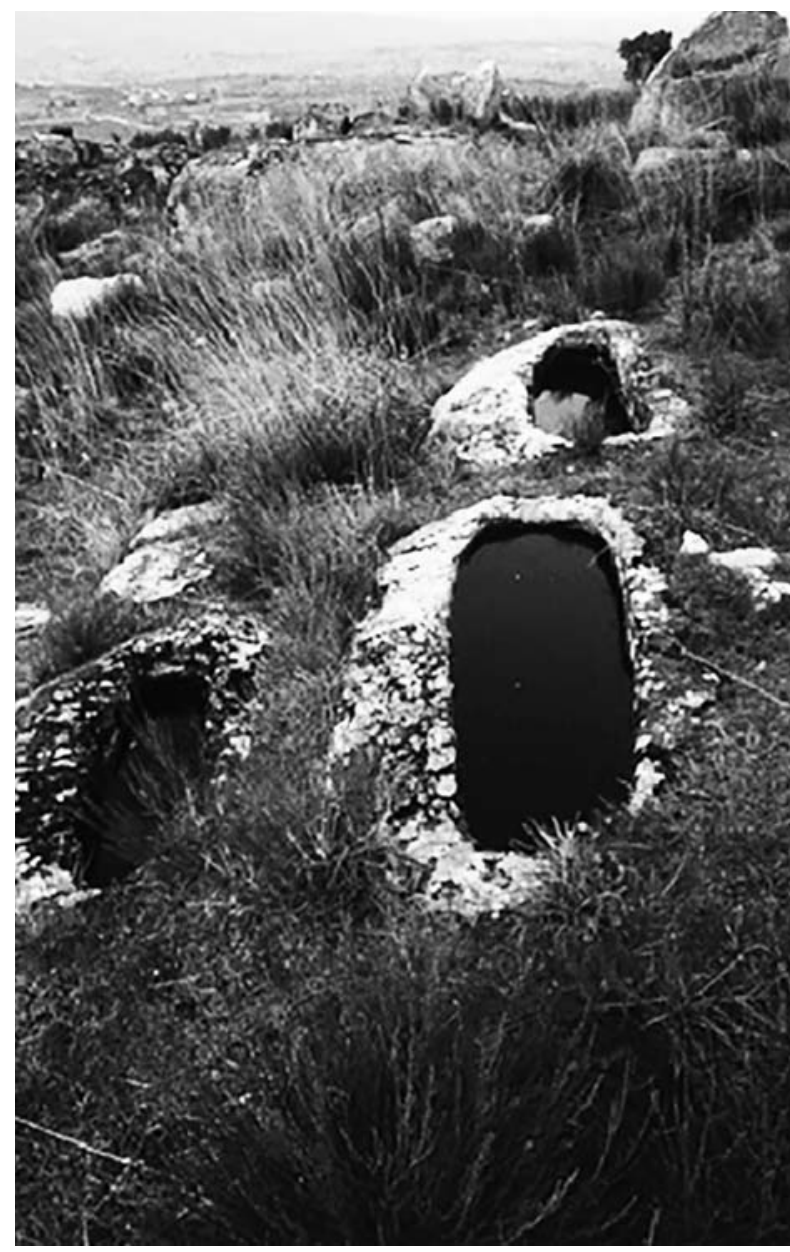

Fig. 5. Sepulturas de la necrópolis de la Tapada do Anjo (Fornos de Algodres). En una suave ladera se distribuyen 22 sepulturas que se organizan en pequeños conjuntos, como el que se muestra en la fotografía, o aparecen dispersas. La necrópolis ocupa un área de cerca de 20 ha. / Tombs from the Tapada do Anjo's necropolis (Fornos de Algodres). It is located in a smooth slope where 22 tombs were excavated, occupying an area with 20 ha. The tombs were organized in small groups as the picture shows.

dir otras, dispersas y que no parecen asociarse espacialmente a ningún otro ejemplar.

Este patrón se repite también en las necrópolis de Soito/Outeiro Negro (Celorico da Beira) con 14 sepulturas organizadas en cuatro núcleos, en la de A-das-Pedras y en la de Colícias (Celorico da Beira) cercanas entre sí, y en el yacimiento de Risado (Gouveia), cuyo análisis detallado presentamos más adelante. En todos los casos estudiados las sepulturas se agrupan por conjuntos, a veces asociando sepulturas infantiles y juveniles. Esta disposición parece respaldar la interpretación de que estos grupos corresponden a espacios sepulcrales de una misma familia. A pesar de agrupar más de 10 sepulturas, estos espacios difícilmente pueden ser vistos como espacios funerarios de entidades supra-familiares, sino como una suma de es-

\footnotetext{
${ }^{1}$ La única excepción es la necrópolis de A-das-Pedras (Celorico da Beira), cuyas 14 sepulturas organizadas en tres núcleos son, todas, no antropomórficas (Tente, 2007: 59-60).
} 
pacios funerarios familiares que se encuentran distantes entre sí, a veces varios centenares de metros. Una vez más la excepción a esta regla es S. Gens.

Por último, es importante destacar que la totalidad de los yacimientos agrupados en esta categoría están asociados a manchas de dispersión en superficie de materiales cerámicos, tanto de uso común como de construcción (sobre todo tejas).

\subsubsection{El yacimiento de Risado (Arcozelo, Gouveia)}

El yacimiento de Risado se sitúa en una ladera de pendiente suave, con fácil acceso a cursos de agua, en las cercanías del valle de la rivera Gouveia, uno de los valles más productivos y desarrollados de la región. Hoy en día este valle abastece de productos agrícolas a los mercados de toda la región, mostrando así su riqueza. La prospección intensiva de este sector ha permitido identificar un total de 13 sepulturas dispersas, incluyéndose una infantil y una inacabada. En el área que rodea las sepulturas se documentaron evidencias de ocupación, destacando el hallazgo de diferentes estructuras realizadas en piedra, cerámica común y de construcción. A pesar del interés que levanta el yacimiento no ha podido acometerse, todavía, su excavación, manteniéndose su identificación con una posible villa romana (Alarcão, 1993: 25).

Existe un camino, actualmente utilizado por pastores y agricultores de las tierras cercanas, que atraviesa el yacimiento. Las sepulturas se sitúan en la zona más elevada, diseminadas, aunque se pueden observar dos grupos algo más concentrados (figura 6). El conjunto situado al noreste (núcleo 1) tiene tres sepulturas y un esbozo de tapa monolítica (Tente y Martins, 1994; Tente y Lourenço, 1998; Tente, 2000 y 2010). Al otro lado del camino, al suroeste de este núcleo, se sitúa otra concentración de sepulturas, con 6 ejemplares (núcleo 2). Además de las propias sepulturas, se pueden observar otras estructuras excavadas en la roca: en un afloramiento se observan dos agujeros circulares de 36 y $45 \mathrm{~cm}$ de diámetro y cerca de $30 \mathrm{~cm}$ de profundidad; $y$ en otro roquedo se tallaron escalones, situándose en la zona más alta un agujero de unos $10 \mathrm{~cm}$ de diámetro. Al oeste de este segundo núcleo se sitúan otras tres sepulturas (núcleo 3), una de ellas destinada a un niño de corta edad. Al norte de estas se localiza una sepultura que no llegó a terminarse. Otra de las sepulturas, localizada algo más al sur, fue transformada en bebedero para animales en una utilización posterior.

No se realizó ninguna intervención arqueológica en este yacimiento, aunque una excavación ilegal que tuvo lugar en 1999 sacó a la luz la parte superior de un muro de piedra, al que se asociaban tejas (ímbrices y tégulas), ladrillos y cerámica común, entre la que destaca un jarro de cocción oxidante y decoración de cordones digitados e incisiones de líneas onduladas, de cronología post-romana, probablemente situada entre los ss. V y VII.

Sin más datos, por el momento, planteamos dos hipótesis para su interpretación. Podría tratarse de un sitio rural romano (¿granja o villa?) que se desestructura y evoluciona hacia un tipo de poblamiento polinuclear al que se asocian los núcleos de las sepulturas. O, quizá, pudiera corresponder a un asentamiento romano abandonado cuyo antiguo territorio vuelve a ocuparse en un momento

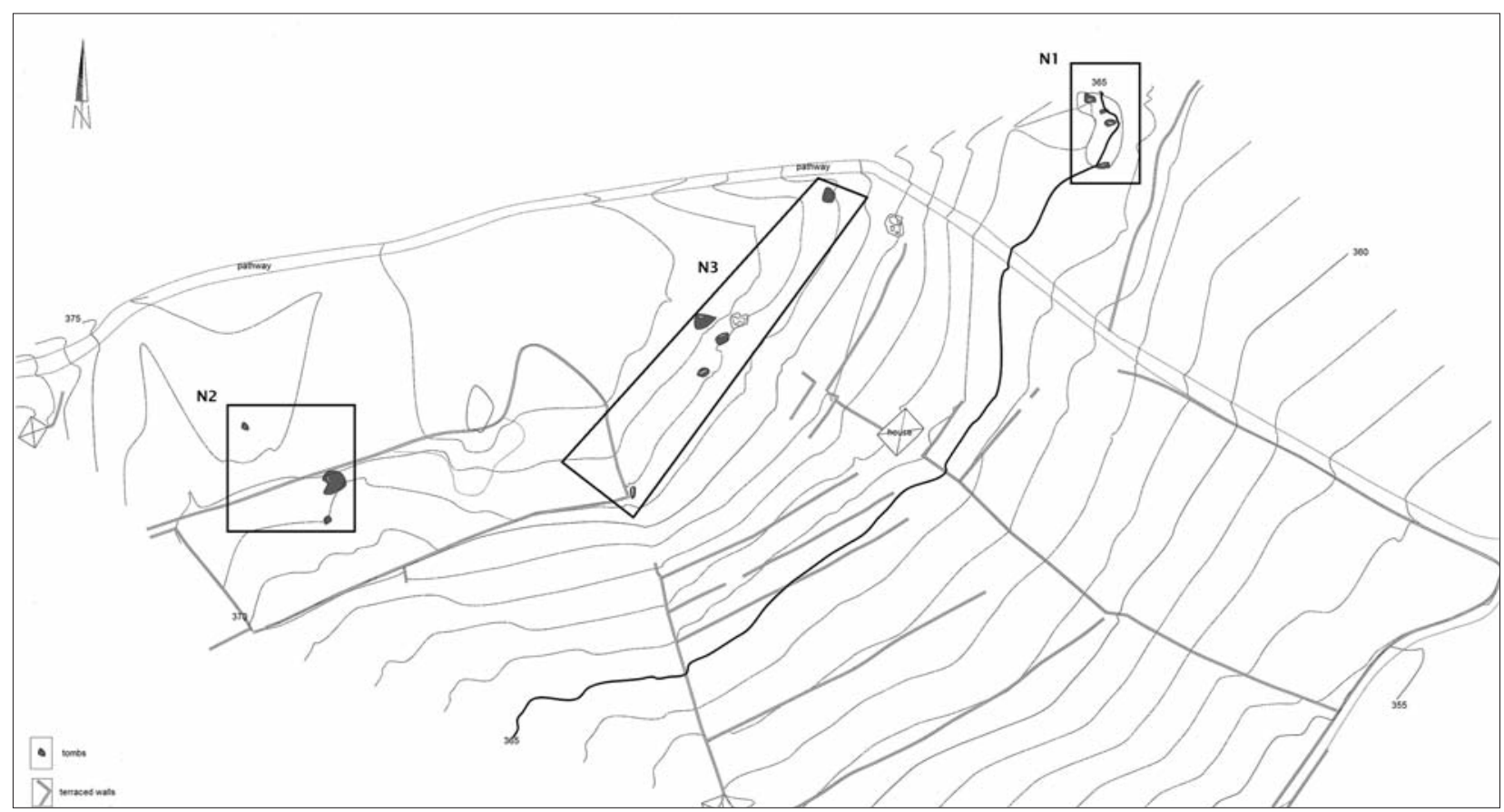

Fig. 6. Planta del yacimiento de Risado (Gouveia), con indicación de los bancales agrícolas y de las sepulturas, con la identificación de los núcleos propuestos. El área representada corresponde al espacio de dispersión de materiales cerámicos en superficie / Risado's (Gouveia) topographic plan. It is indicated the tombs and the groups that are proposed in this study. All the area of this plan has medieval ceramic remains in the soil superficie. 
posterior ante la facilidad de acceso a materiales de construcción y por situarse en una zona propicia para el cultivo. En este caso es igualmente posible que el espacio habitado pudiera estructurarse en diversos núcleos, probablemente asociados a los grupos de sepulturas, sin que esto implique necesariamente la contemporaneidad entre ellos. Por lo tanto, no estaríamos hablando de una necrópolis en el sentido de un espacio funerario bien definido por la comunidad que lo utilizaba, sino que se trataría de la asociación, por proximidad espacial, de varios grupos reducidos de sepulturas que estarían vinculados con un espacio productivo y habitacional unifamiliar.

\subsubsection{El yacimiento de S. Gens (Celorico da Beira)}

S. Gens se sitúa a $2 \mathrm{~km}$ al norte de Celorico da Beira, perteneciendo a la freguesía de Santa María. Su situación topográfica no es llamativa, de hecho se sitúa en un valle definido por la confluencia de la rivera Tamanhos con el río Mondego. El yacimiento se extiende por una amplia superficie, dividiéndose en diversos núcleos de ocupación: una necrópolis de sepulturas excavadas en la roca, dos núcleos con vestigios romanos y un poblado altomedieval, además de un pequeño abrigo natural con una ocupación prehistórica (neolítica o calcolítica). Se han realizado varias campañas de excavaciones arqueológicas entre 2008 y 2013, dirigidas por la autora de este trabajo, centrándose en el poblado altomedieval y en una estructura romana de tipo granja².

La intervención arqueológica en el poblado altomedieval permitió identificar una ocupación formada por varias unidades domésticas con características materiales infrecuentes en el registro arqueológico. Dichas estructuras domésticas revelaron características interesantes: la ausencia total de muros, hornos, suelos de cabañas e incluso de agujeros de postes. Las estructuras y el mobiliario habrían sido fabricados con materiales orgánicos perecederos, parte de los cuales pudieron recuperarse gracias a que ardieron y se preservaron en el registro. Las hogueras constituyen la evidencia arqueológica más clara, junto con los fragmentos cerámicos. Las excavaciones llevadas a cabo en el verano de 2012 permitieron la identificación de contextos con un gran número de restos de fauna excepcionalmente conservados (actualmente en estudio). Las cabañas del poblado se construyeron en afloramientos cercanos a la cara interna de la empalizada defensiva. La etnografía aporta algunos paralelos interesantes que ayudan a interpretar estas evidencias arqueológicas, permitiendo su detallada reconstrucción. Un trabajo etnográfico clásico acerca de la arquitectura tradicional portuguesa de ámbito rural describe un tipo de estructuras de hábitat que son cabañas cónicas, conocidas como choupanas (chozas o chamizos), de planta circular y construidas por completo con materiales perecederos, sin que fuera preciso la fijación de postes en el suelo (Oliveira, Galhano, Pereira, 1969; Tente, 2011). El poblado de S. Gens se encontraba cercado por una estructura de piedras que servía de base a una empalizada construida, fundamentalmente, con troncos de roble negro (Quercus pyrenaica) y, en menor medida, de encina (Quercus rotundifolia), correspondiendo al primero el 84,2 \% de los macrorrestos vegetales estudiados, y un 13,2 \% al segundo (Queiroz, 2009; Tente, 2010). El recinto presenta una planta de tendencia ovalada, apenas transformada por la entrada en embudo, que forma una especie de atrio o patio, orientada hacia el noreste (figura 7), protegido por un conjunto de tors, de elevada altura, en los que todavía es posible observar entalles en la roca que servirían de calzo para la estructura o plataforma desde la que se vigilaría el acceso al poblado.

Las primeras noticias que tenemos sobre S. Gens hacen referencia, como no podía ser de otra manera, a la necrópolis de sepulturas excavadas en la roca. Su principal característica reside en el elevado número de sepulturas que la forman. Las mayores necrópolis estudiadas en la región - Matança y Tapada de Anjo, en el término de Fornos de Algodres - tienen alrededor de 22 sepulcros (Valera, 1990; Tente, 2007), lejos de las 54 documentadas en S. Gens. Conviene señalar que este número sería, sin duda, superior, dado que el trabajo de recogida de información oral permitió confirmar que algunas sepulturas se destruyeron durante el proceso de extracción de piedra para la construcción del lagar de aceite, situado en la confluencia del Tamanhos con el Mondego. Tampoco parece descabellado pensar que hubo sepulturas que corrieron el mismo fin cuando, durante el reinado de João III (s. XVI), se construyó el Ponte Nova sobre el Mondego (Neto, 2009), situado a pocos metros del citado lagar.

Las sepulturas se encuentran dispersas por la ladera, agrupándose por proximidad, en un patrón semejante a los pequeños grupos de hasta nueve sepulturas o a las necrópolis desordenadas de menor dimensión (figura 6). Por relaciones de mayor proximidad espacial, podemos proponer la existencia de 6 agrupamientos o núcleos, señalados en la Tabla 1. El primero de ellos está compuesto por 7 sepulturas, y se localiza junto a la muralla del poblado medieval. El núcleo 2 es el más numeroso, y el más concentrado espacialmente; se encuentra marcado por la presencia de un elemento pétreo destacado en forma de seta visible desde cualquier punto del yacimiento (figura 7). Este núcleo incluye 18 sepulturas, entre ellas tres infantiles, dominando la tipología no antropomorfa. Al noroeste de este grupo más concentrado se sitúan otras dos sepulturas, que hemos considerado como un conjunto in-

\footnotetext{
2 Los núcleos romano y altomedieval se encuentran separados por unos 100 m, habiéndose realizado las excavaciones de dichos núcleos de manera autónoma. La granja romana ha sido excavada por António Marques (arqueólogo de la Câmara Municipal de Celorico da Beira). Los resultados obtenidos hasta ahora indican el abandono del sitio a finales del s. IV o, como muy tarde, a principios del s. V. (Marques, 2011; Lobão, Marques e Tente, 2013)
} 
dividualizable de esta necrópolis (núcleo 3). Otro grupo (núcleo 4) puede delimitarse en el área más al noroeste, conteniendo ocho sepulturas, entre ellas una infantil. Al sur de este grupo y al norte del grupo 2 se encuentran dispersas otras 14 o 15 sepulturas, cuya interrelación espacial sugiere la asignación a otro grupo (núcleo 5). Este conjunto incluye una sepultura destinada a un enterramiento infantil, y las sepulturas de tipo no antropomorfas son mayoritarias. Al suroeste se dispersan otras cuatro se-

\begin{tabular}{|c|c|c|c|c|}
\hline Tumba & Tipología & Orientación & Tamaño & Núcleo \\
\hline 1 & No antropomorfa & $S-N$ & Adulto & N1 \\
\hline 2 & No antropomorfa & $N-S$ & Adulto & N1 \\
\hline 3 & antropomorfa & NO-SE & Adulto & N1 \\
\hline 4 & antropomorfa & NO-SE & Adulto & N1 \\
\hline 5 & antropomorfa & NO-SE & Adulto & N1 \\
\hline 6 & antropomorfa & SO-NE & Adulto & N1 \\
\hline 7 & antropomorfa & $N-S$ & Adulto & N1 \\
\hline 9 & No antropomorfa & SO-NE & Infantil & N2 \\
\hline 10 & No antropomorfa & $N-S$ & Adulto & N2 \\
\hline 11 & No antropomorfa & $O-E$ & Adulto & N2 \\
\hline 12 & No antropomorfa & NO-SE & Infantil & N2 \\
\hline 13 & No antropomorfa & SO-NE & Infantil & N2 \\
\hline 14 & antropomorfa & SO-NE & Adulto & N2 \\
\hline 15 & No antropomorfa & $O-E$ & Infantil & N2 \\
\hline 16 & antropomorfa & $O-E$ & Adulto & N2 \\
\hline 17 & No antropomorfa & SO-NE & Adulto & N2 \\
\hline 18 & No antropomorfa & SO-NE & Adulto & N2 \\
\hline 19 & No antropomorfa & $O-E$ & Adulto & N2 \\
\hline 20 & antropomorfa & NO-SE & Adulto & N2 \\
\hline 21 & antropomorfa & NO-SE & Adulto & N2 \\
\hline 22 & antropomorfa & SE-NO & Adulto & N2 \\
\hline 23 & antropomorfa & $S-N$ & Adulto & N2 \\
\hline 24 & No antropomorfa & $O-E$ & Adulto & N2 \\
\hline 25 & No antropomorfa & NO-SE & Adulto & N2 \\
\hline 26 & No antropomorfa & SO-NE & Adulto & N2 \\
\hline 27 & antropomorfa & SO-NE & Adulto & N3 \\
\hline 28 & antropomorfa & SO-NE & Adulto & N3 \\
\hline 29 & antropomorfa & $O-E$ & Adulto & N4 \\
\hline 30 & antropomorfa & NO-SE & Infantil & N4 \\
\hline 31 & antropomorfa & $N-S$ & Adulto & N4 \\
\hline 32 & antropomorfa & NO-SE & Adulto & N4 \\
\hline 33 & No antropomorfa & $S-N$ & Adulto & N4 \\
\hline 34 & antropomorfa & NO-SE & Adulto & N4 \\
\hline 35 & No antropomorfa & NO-SE & Adulto & N4 \\
\hline 36 & No antropomorfa & $N-S$ & Adulto & N4 \\
\hline 8 & antropomorfa & $O-E$ & Adulto & N5 \\
\hline 37 & antropomorfa & NO-SE & Adulto & N5 \\
\hline 38 & No antropomorfa & $E-O$ & Adulto & N5 \\
\hline 39 & No antropomorfa & $O-E$ & Adulto & N5 \\
\hline 40 & No antropomorfa & NO-SE & Adulto & N5 \\
\hline 41 & No antropomorfa & SE-NO & Infantil & N5 \\
\hline 42 & No antropomorfa & SO-NE & Adulto & N5 \\
\hline 43 & antropomorfismo incipiente & $N-S$ & Adulto & N5 \\
\hline
\end{tabular}

pulturas (posiblemente cinco, si consideramos que la sepultura 50 no pertenece al núcleo 5) que se consideró que pudieran constituir otro nuevo núcleo (6), aunque en este caso no resulta clara la relación espacial entre los sepulcros y los demás grupos descritos. Por último, situado a unos $750 \mathrm{~m}$ de la entrada del poblado, se encuentran otras dos sepulturas (no integradas en la figura 6 ni en la tabla), que dada la distancia que las separa no parece que puedan formar parte de esta necrópolis.

\begin{tabular}{|c|c|c|c|c|}
\hline Tumba & Tipología & Orientación & Tamaño & Núcleo \\
\hline 44 & No antropomorfa & NO-SE & Adulto & N5 \\
\hline 45 & antropomorfismo incipiente & SO-NE & Adulto & N5 \\
\hline 46 & No antropomorfa & NO-SE & Adulto & N5 \\
\hline 47 & No antropomorfa & SO-NE & Adulto & N5 \\
\hline 48 & No antropomorfa & SE-NO & Adulto & N5 \\
\hline 49 & No antropomorfa & SO-NE & Adulto & N5 \\
\hline 50 & antropomorfa & SO-NE & Adulto & N5 o 6? \\
\hline 51 & antropomorfa & O-E & Adulto & N6 \\
\hline 52 & $?$ & NO-SE & $?$ & N6 \\
\hline 53 & antropomorfa & O-E & Adulto & N6 \\
\hline 54 & No antropomorfa & SO-NE & Adulto & N6 \\
\hline
\end{tabular}

Tabla 1: Lista de las sepulturas de la necrópolis desordenadas de S. Gens, con la indicación de su tipología, la orientación, el tamaño y su posición dentro de la necrópolis (núcleo al que se adscribe) / São Gens necropolis: indication of topology, orientation, size and nucleus of belonging of each grave.

Desde el punto de vista de la tipología, las sepulturas no antropomorfas representan el $52 \%$ del total, con una cierta variabilidad de los tipos representados dentro de esta categoría. Las sepulturas antropomorfas (23 ejemplares) presentan también varios subtipos. Las orientaciones de los sepulcros son tan diversas como las propias tipologías, documentándose orientaciones hacia casi todos los cuadrantes. Sí podemos señalar que, la mayoría, se orientan hacia el este, noreste y sureste (Tabla 1). Dos de las sepulturas destinadas a niños se encuentran sin acabar, tal y como sucede con 4 sepulturas destinadas a adultos, siendo, por tanto, seis las tumbas inacabadas en esta necrópolis.

La gran dispersión que se observa en esta necrópolis, así como la aparente desorganización en la disposición de los sepulcros, transmite la idea de una falta de lógica interna del espacio funerario. Sin embargo, conviene resaltar tres datos fundamentales para su interpretación: se advierte la existencia de grupos de sepulturas que parecen corresponder a 5 -quizá 6- núcleos familiares que se encuentran alejados espacialmente entre sí; la exclusión del interior del poblado como espacio funerario; y la ausencia de restos materiales de cronología altomedieval fuera del área del asentamiento, lo que sugiere la concentración del espacio habitacional. Una vez más, puede observarse un patrón de organización familiar, aunque en el caso de S. Gens las áreas habitacionales ocupadas por esas familias se concentren en un espacio limitado, y delimitado, por una cerca y una empalizada. Por el momento no es posible 
comprender los criterios de elección de la localización espacial de cada núcleo, así como el de cada sepultura dentro de su respectivo núcleo, pero obedecerían a reglas establecidas por la comunidad, posiblemente en una lógica similar a la que explique la distribución del espacio en el interior del poblado o de las parcelas de tierra para el cultivo o el pastoreo que les estarían asignadas.

La necrópolis de S. Gens puede ser datada por las cronologías obtenidas en la excavación del poblado, que ha sido fechado en el siglo $X$ gracias a las dataciones sobre muestras vegetales procedentes de contextos arqueológicos seguros. De otro lado, cabe destacar que el poblado de S. Gens fue destruido por un incendio en la segunda mitad de esa centuria (Tente y Carvalho, 2011).Consideramos probable que dicho poblado haya estado habitado durante tres o cuatro generaciones, intervalo temporal que correspondería también a la utilización de la necrópolis.

\subsection{Necrópolis ordenadas}

Sólo un reducido porcentaje de los yacimientos con sepulturas del Alto Mondego pueden integrarse en la ca- tegoría de las necrópolis ordenadas. Son los siguientes cuatro casos: Monte Aljão (Gouveia), Gouveia (centro de la localidad), Mangualde (localidad) y Algodres (Fornos de Algodres). Excepto en Gouveia, estos sitios fueron objeto de excavaciones arqueológicas y tienen como característica principal reunir en un espacio muy limitado una gran cantidad de sepulturas que presentan alineamientos entre sí y que respetan una orientación dominante.

En el caso de Gouveia se supone la existencia de este tipo de necrópolis por la referencia a la aparición de sepulturas rupestres alineadas en la actual Plaza de S. Pedro, en el centro de la localidad (Ferreira, 1953), y que estarían situadas en el exterior del castillo medieval de Gouveia. Ante la ausencia de excavaciones recientes en esta área, no podemos aportar más datos.

Más recientemente, en el transcurso de una serie de obras de remodelación urbana, se excavó una necrópolis medieval agrupada y alineada con el edificio religioso de la aldea de Algodres (concelho de Fornos de Algodres). La datación mediante radiocarbono obtenida para un enterramiento en una sepultura excavada en la roca perteneciente a la primera fase de la necrópolis (Soares y Cardoso, 2004) dio como resultado el siglo XIII (Tente y

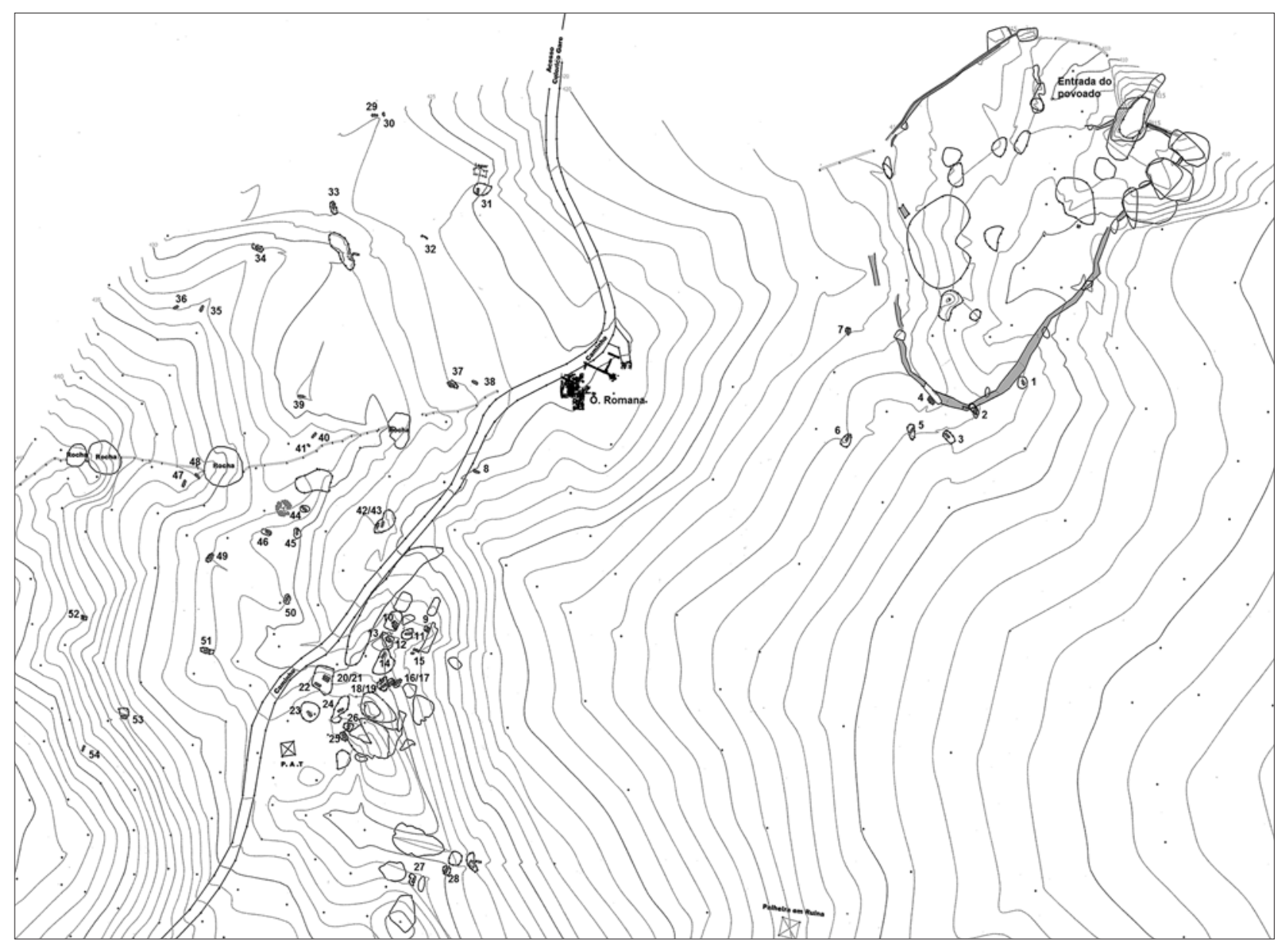

Fig. 7. Levantamiento topográfico del yacimiento de S. Gens, con indicación de las estructuras romanas, del poblado alto medieval y de las sepulturas / S. Gens's topographic plan. It is indicated the roman structures, the medieval enclosure and the tombs from the necropolis. 


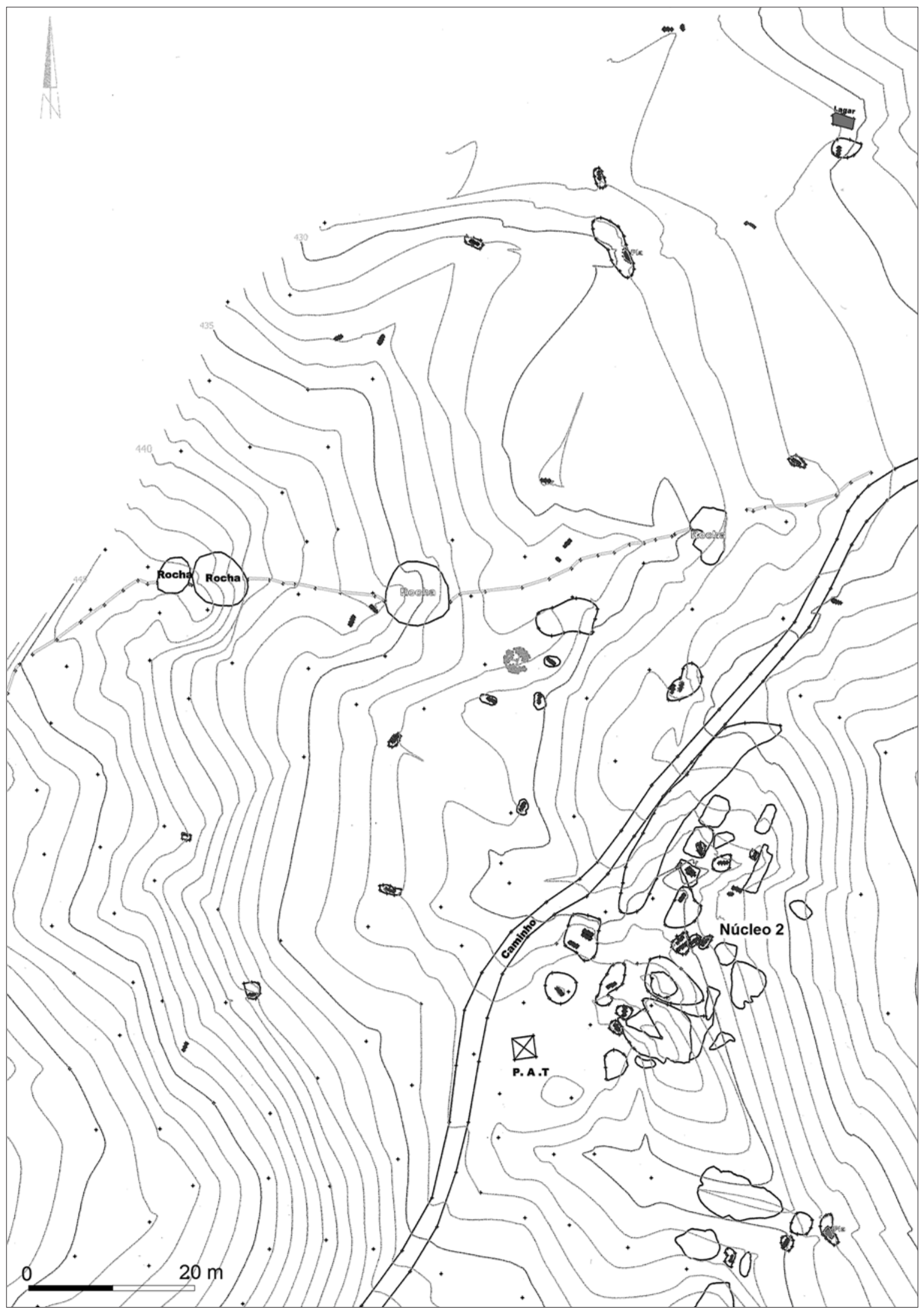

Fig. 8. Detalle del levantamiento topográfico de la necrópolis: núcleo 2 y conjuntos de sepulturas dispersas al noroeste y al sur de este núcleo / Detail of topographic plan of S. Gens's necropolis: group 2 and tombs scattered in the northwest and south areas. 


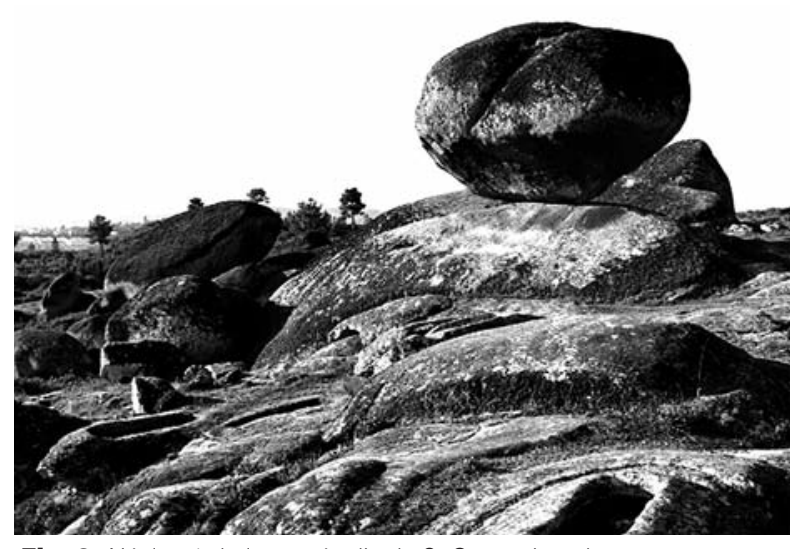

Fig. 9. Núcleo 1 de la necrópolis de S. Gens, vista de noreste-suroeste (fotografía de Carlos Simões) / View northeast-southwest of group 2 of S. Gens's necropolis (photography by Carlos Simões).

Carvalho, 2011). No es de esperar que esta necrópolis alineada con un edificio religioso pueda retrasarse a un periodo anterior al siglo XII, momento en el que debió producirse el proceso de parroquialización vinculado a la reforma administrativa y litúrgica de la iglesia peninsular, iniciada en el Concilio de Burgos, pero que sólo en el siglo XII (o incluso en el XIII) habría sido aplicado en esta región (Nogueira, 2004: 142). El cementerio parroquial habrá funcionado durante varios siglos, probablemente hasta el s. XIX, por lo que es lógica la existencia de varios niveles de ocupación y la superposición constante de sepulturas, que superan los 230 enterramientos. Sin embargo, es importante resaltarlo, estos casos no pueden considerarse como una necrópolis medieval, sino como un espacio funerario parroquial con una utilización plurisecular.

Se trata, por tanto, de casos en los que las sepulturas están dispuestas alineadas entre sí y en correlación espacial con espacios religiosos, cuya cronología puede remontar hasta los siglos XII o XIII. Las sepulturas excavadas en la roca se asocian a otras formas de inhumación, y son habituales las superposiciones y el corte de sepulturas por otras posteriores, lo que refleja una tendencia hacia la despersonalización de las sepulturas (al menos de parte de ellas). En estos casos la identidad y la ancestralidad de la sepultura no parece ser lo más importante. Este aspecto es sustituido por el sentimiento de pertenencia a una comunidad más amplia que comparte, sobre todo, la misma doctrina, la misma iglesia (Martín Viso, 2008). Este fenómeno alteró de manera indeleble la forma de enterrar a los difuntos, pero refleja sobre todo la existencia de un poder (exterior y supra-local) regulador y organizador de la vida religiosa, social y económica de las comunidades.

Aparentemente, la única excepción a esta regla es el caso de Monte Aljão, donde se presupone la existencia de un edificio religioso (aunque no pudo ser identificado en las intervenciones arqueológicas), y una cronología para la necrópolis que pudiera retrasarse más allá del siglo XII. La existencia de datos arqueológicos permite explicar con mayor detalle este yacimiento en el apartado siguiente (Tente, 2010).

\subsubsection{El yacimiento de Monte Aljão (Gouveia)}

El yacimiento de Monte Aljão se sitúa en la freguesia de Rio Torto, en el municipio de Gouveia. El topónimo hace referencia a un área más o menos plana rodeada por el río Mondego al norte y por el Torto al oeste. En este yacimiento se han llevado a cabo dos excavaciones arqueológicas, la primera, realizada en los años 80 del siglo pasado, fue una intervención de urgencia originada por la realización de trabajos agrarios; la segunda, realizada por la autora de este trabajo entre los años 2008 y 2009 e integrada dentro de un proyecto de investigación. Los resultados nos han permitido constatar la práctica destrucción del yacimiento durante el proceso de plantación de un viñedo en los años 80 del siglo pasado, apenas conservándose algunos muros de cronología medieval superpuestos a un edificio romano.

Los niveles de ocupación altomedievales presentaban un bajo nivel de conservación. No obstante, se documentaron también 15 sepulturas excavadas en la roca, 8 de las cuales fueron excavadas en la campaña de 20082009. En dicha campaña se consiguieron excavar algunas tumbas intactas (figura 10), aunque no revelaron ningún ajuar ni siquiera restos conservados, lo que impide una datación precisa del yacimiento.

Con los datos obtenidos hasta el momento, podemos afirmar que el yacimiento de Monte Aljão tuvo una ocupación inicial en el siglo II d.C., perdurando hasta el siglo IV o inicios del siguiente. Posteriormente el espacio vuelve a ser ocupado, reaprovechando parcialmente las estructuras romanas. Sin embargo no se consiguió datar el momento inicial de esta reocupación. A partir de los materiales cerámicos -recogidos en niveles revueltos por la viña- con paralelos directos en la región, podemos plantear que dicha reocupación tuvo lugar en el siglo IX.. La ocupación altomedieval de Monte Aljão pervive por lo menos hasta mediados del s. XII, momento en el que esta propiedad rural aparece mencionada en la documentación perteneciente al Monasterio de Santa Cruz de Coimbra (Tente, 2010: 52-114).

Lo singular de esta necrópolis respecto al panorama observado en el Alto Mondego reside en la concentración de las sepulturas y en su alineamiento, además de su orientación hacia el este. Aunque sólo se intervino en una pequeña parte del área ocupada por la necrópolis, parece distinguirse la existencia de una zona preferente reservada a enterramientos infantiles. Este espacio habría sido excavado parcialmente en las campañas de los años 80 , identificándose 7 sepulturas de pequeñas dimensiones. Los trabajos de 2008 y 2009 revelaron de nuevo varias sepulturas infantiles (figura 11). La organización y la orientación dominante de las sepulturas, unido al hecho de que es probable que existiera un espacio reservado para enterramientos infantiles, sugiere que la necrópolis estaría asociada a una iglesia.

La gestión del cementerio correspondería, por tanto, al poder religioso que substituiría así a la organización familiar de las necrópolis desordenadas. Esta idea vendría reforzada por la superposición de las sepulturas, algo que 
invita a pensar en su despersonalización, al menos en lo que respecta a las de la primera fase de la necrópolis. Todo indica que nos encontramos ante un cementerio muy concentrado, donde la gestión del espacio disponible resultaba fundamental a la hora de acoger nuevos enterramientos. La organización y la disposición de las sepulturas no se realizarían de acuerdo con la existencia de grupos familiares, aunque sin dejar de admitir que pudiera existir la reutilización de una sepultura por miembros de una misma familia. La memoria de aquellos difuntos que ocupan las sepulturas más antiguas desaparecerá sólo cuando resulte más importante el hecho de ser inhumado en el espacio de la comunidad, junto al centro religioso, que ser enterrado junto a los miembros de la propia familia. Este proceso debió generalizarse sólo tras la implantación del fenómeno parroquial, es decir, a partir del momento en el que la iglesia y su cementerio congregan y se apropian de todo el fenómeno religioso que vive el individuo. El individualismo da paso al anonimato del cementerio parroquial. La Iglesia asume, desde ese momento, el monopolio de la memoria social, donde prima ahora el sentido de comunidad parroquial (Martín Viso, 2014: 139). Este proceso se inicia, en el espacio en estu- dio, ya en el siglo XII. Esto tampoco ayuda a definir la cronología de la necrópolis, dado que en el documento que señala la venta de esta propiedad de Aljian, que Afonso Henriques hace en 1140 (doc. 52 del Libro Santo de Santa Cruz, cf. Ventura, Faria, 1990: 223-224), no aparece ninguna referencia a una iglesia o a su necrópolis, y ésta no llegará a convertirse en parroquia pleno medieval. Es posible, por tanto, que Monte Aljão señale el primer momento, en el Alto Mondego, en el que los cementerios se concentran y tienden a ser más despersonalizados, algo que, en este caso particular, puede haber sucedido entre el siglo XI y la primera mitad del s. XII.

\section{3.- DISCUSIÓN}

El patrón de distribución espacial de las sepulturas excavadas en la roca del Alto Mondego está marcado por la escasa presencia de espacios funerarios que reúnan más de 10 sepulturas. Como se ha demostrado a lo largo de este artículo, en el Alto Mondego las necrópolis son una realidad minoritaria, siendo el modelo dominante el de las sepulturas aisladas y los agrupamientos dispersos, que suponen el 88 $\%$ del total de los sitios identificados.

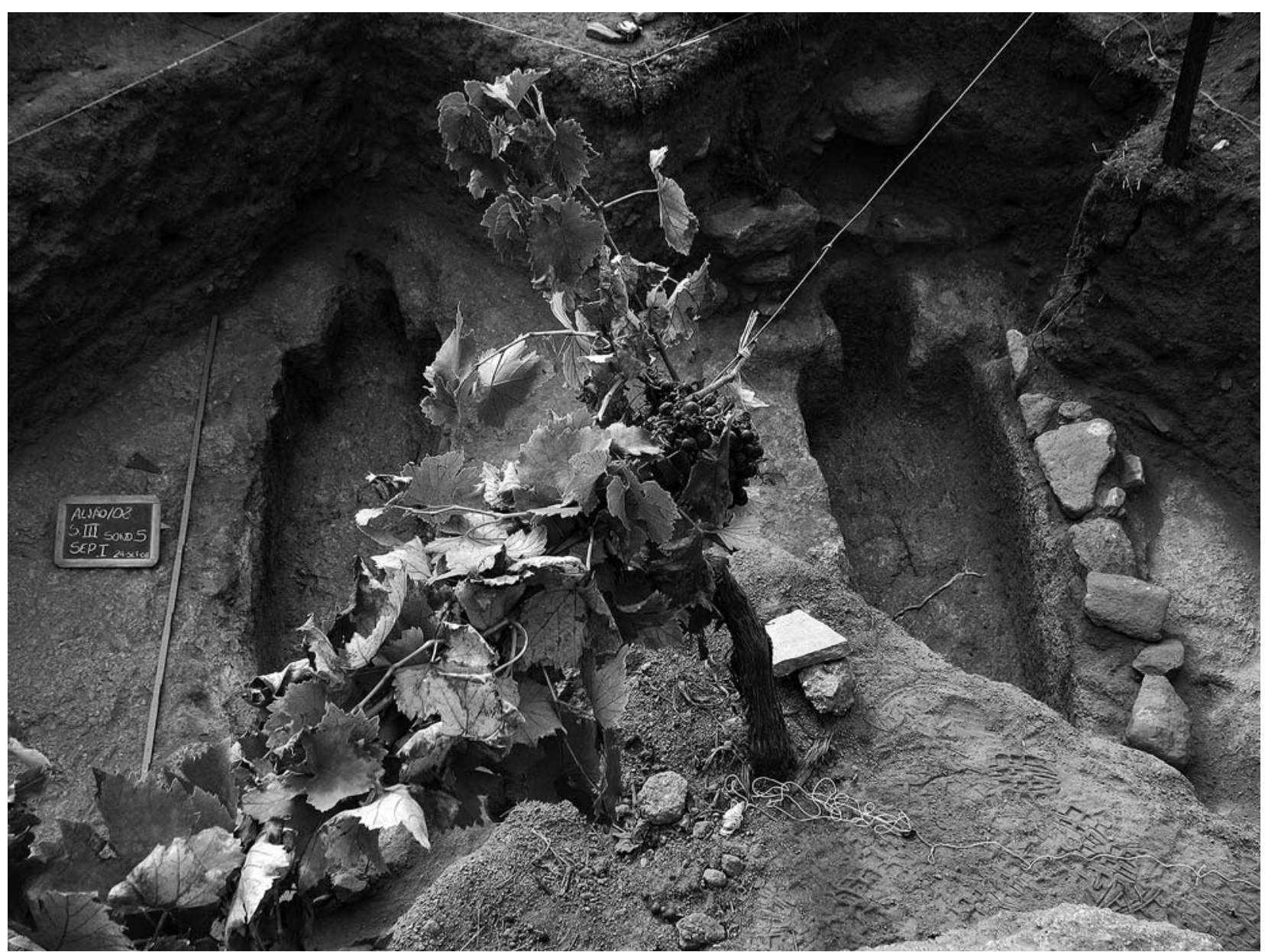

Fig. 10. Monte Aljão (Gouveia): tumbas intactas identificadas en 2008. No revelaron ningún ajuar ni huesos / Monte Aljão (Gouveia): intact tombs recovered in the 2008 archaeological campaign. They did not revealed human remains neither grave goods. 


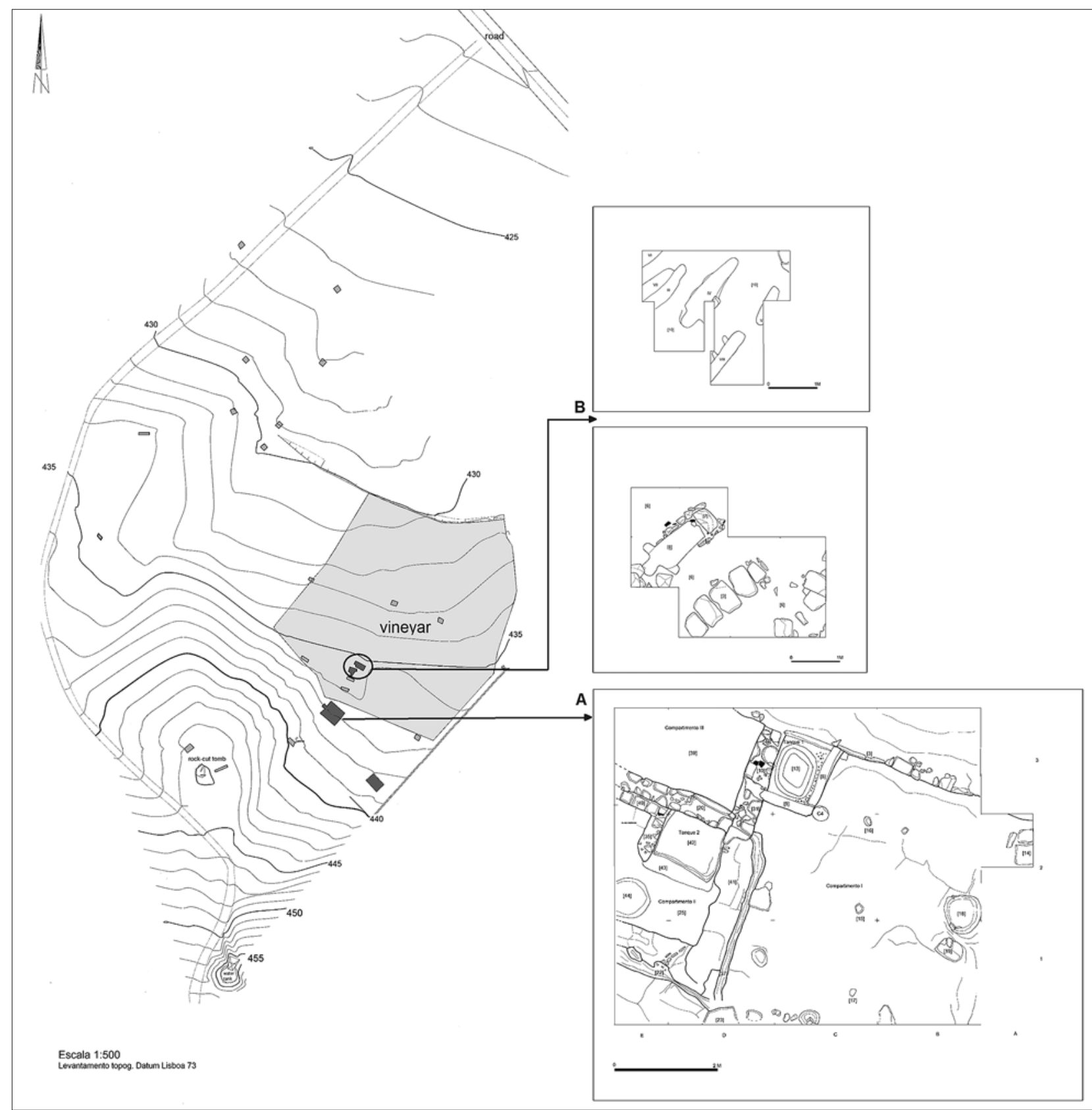

Fig. 11. Levantamiento topográfico de Monte Aljão, con indicación de las áreas con estructuras romanas (A) y de la necrópolis (B) / Monte Aljão's topographic plan. It is indicated the roman structures and the necropolis that were identified in the archaeological excavations.

Esta situación se documenta también en regiones vecinas. Los estudios desarrollados por Marina A. Vieira (2004) en el Alto Paiva identificaron también este patrón: de los 32 sitios con sepulturas excavadas en la roca identificados, en 15 se registraron sepulturas aisladas y sólo en 3 de los yacimientos se documentaron ocho o más sepulturas. También en el trabajo de Sandra Lourenço (2007) en la cuenca del Rio Alva (afluente del Mondego) se observa la misma situación: de 85 sitios identificados con sepulturas excavadas en la roca, 30 presentan sólo una sepultura; en 34 casos se identificaron 2 o 3, y tan sólo en
3 yacimientos se conocen más de 10 sepulcros, uno de ellos con más de 20 tumbas (en concreto 27). En el área de Viseu, el trabajo llevado a cabo por Jorge A. Marques (2000) muestra un patrón parecido, es decir, un 31,5\% de los sitios sólo tiene un sepulcro; en un $43,9 \%$ se identificaron 2 o 3 sepulturas; en el 17,4\% de los yacimientos se conocen pequeñas necrópolis de 4 a 10 sepulturas y sólo un 2,8 \% de los casos registran más de 10 sepulcros. Parece observarse, claramente, una pauta común en la Beira Interior, en concreto en su zona central y oriental, que tiende a la dispersión de sepulturas en detrimento de la 
existencia de grandes necrópolis concentradas. Esta situación está en consonancia con la falta de referencias documentales que mencionen iglesias anteriores al siglo XII, que también se encuentran prácticamente ausentes en el registro arqueológico rural ${ }^{3}$.

Los primeros registros arqueológicos fiables de iglesias y la mención documental a edificios religiosos en el Alto Mondego son tardíos, no pudiendo retrasarse más allá de la segunda mitad del siglo XII o principios del XIII'. Es en esa altura cuando los espacios funerarios rupestres tienden a desaparecer, pasando a situarse los enterramientos alrededor de la iglesia parroquial, como se ha documentado en el caso de Algodres. La única situación en la que no está tan clara esta correlación entre edificios religiosos y necrópolis es el yacimiento de Monte Aljão, donde la arqueología reveló que las sepulturas, que se encuentran alineadas y concentradas, son anteriores al siglo $\mathrm{XI}$, sugiriendo que se encontrarían en torno a una iglesia. También se ha documentado, en este yacimiento, la superposición de sepulturas, tal y como sucede en Algodres, pero no se identificó ningún edificio que se pudiera relacionar con un templo, ni tampoco es mencionado en el documento ya mencionado datado en 1140 .

Este caso es, todavía, una excepción, siendo el modelo predominante aquel que refleja la dispersión de los sepulcros en el territorio y su aparente desorganización en la disposición de las sepulturas cuando estas se asocian entre sí. ¿Qué puede significar esto? ¿Qué nos indica este patrón acerca de las poblaciones que construyeron y utilizaron estos sepulcros? Para Iñaki Martín Viso reflejaría una organización de carácter local con la ausencia de un control estricto por parte de un poder para decidir dónde y cómo se inhuma. La lógica de la familia y de la comunidad parecen emerger de este patrón, frente a la disposición concentrada y alineada de las sepulturas (alrededor, o no, de un centro de poder como una iglesia o un castiIlo) que refleja ya la acción de un poder que es capaz de superponerse a la voluntad individual y familiar. Pero para este autor las sepulturas son más que un simple reflejo de la organización familiar y comunitaria, expresando también una identidad del espacio que está profundamente relacionado con el territorio y su aprovechamiento (Martín Viso, 2012b). Lo que no está claro es si esa relación, que se evidencia a través de la legitimidad otorgada por el espacio funerario de los antepasados, se establece con los espacios de habitación o con los terrenos que explotan la familia y/o la comunidad. Esta pregunta no tiene una solución sencilla, aceptando además que ambas respuestas no se excluyen. Es probable que las sepulturas excavadas en la roca hayan servido, efectivamente, para legitimar la propiedad o el derecho de uso y/o aprovechamiento de los recursos agrarios y forestales, pero también pueden haberse ubicado al mismo tiempo junto a los locales de habitación, como se ha demostrado en los casos presentados a lo largo de este trabajo. Los trabajos de excavación en las necrópolis (Monte Aljão y Algodres) o en sitios de habitación próximos a ellas (Penedo dos Mouros y S. Gens), son las únicos realizados hasta al momento en el Alto Mondego. No obstante, esperamos poder seguir realizando intervenciones arqueológicas en otros sitios. Pero es un trabajo difícil ya que la identificación y localización de estructuras habitacionales o productivas en las áreas anexas a las tumbas excavadas en la roca es complicada debo a la escasez de vestigios en superficie.

Esta cuestión se relaciona estrechamente con otro debate que acompaña a la discusión sobre las sepulturas excavadas en la roca: la relación espacial entre sepulturas y poblamiento. El problema de la relación entre los espacios funerarios y el poblamiento no es un problema nuevo en arqueología, y marca una de las líneas de investigación de la denominada "arqueología de la muerte" desarrollada en las décadas de los años 80 y 90 . Este tema fue abordado como si se tratara de un elemento fundamental para la comprensión del significado de los patrones funerarios de las comunidades segmentarias, pero su tratamiento resulta complicado porque "analysis along single dimensions of mortuary practices will be insufficient" (Chapman y Randsborg, 1981: 14). Sólo un acercamiento multifacetado, que también tenga en cuenta los datos sociales y las limitaciones físicas y ambientales, permitirá ahondar en el conocimiento de estas realidades. Lo cierto es que, desde el inicio, se consiguió un importante progreso desde la perspectiva de la arqueología de la muerte en el caso de los espacios funerarios con restos osteológicos y ajuares funerarios (fundamentalmente pre y protohistóricos). Sin embargo, en lo que respecta a los cementerios rupestres altomedievales, el avance está dificultado por la ausencia generalizada de este tipo de evidencias. Sólo el análisis espacial y los intentos de relacionarlos con el poblamiento (o por lo menos con los espacios usados en vida) han posibilitado algunos progresos, aunque de manera más tardía que los observados para otras cronologías y otras geografías.

En lo que respecta a las sepulturas rupestres altomedievales hay que señalar que desde los trabajos de Mário Barroca (1987; 2010-2011) está patente la idea de vincular directamente las sepulturas excavadas en la roca con el poblamiento rural altomedieval. Esta idea aparece expresada de manera significativa tanto en la bibliografía portuguesa como en la española (Laliena y Ortega, 2005; Álvaro y Padilla, 2012; Rubio Díez, 2011; Martín Viso, 2012a y 2012b). La relación entre sepulturas aisladas y poblamiento disperso fraguó a partir de la recurrente pre-

\footnotetext{
${ }^{3}$ Hay excepciones fuera del territorio del Alto Mondego, como los casos de São Pedro da Lourosa (Oliveira do Hospital).

${ }^{4}$ Para el área occidental de la Beira, en particular para la zona de Lafões, la documentación apunta a la existencia de edificios de culto más antiguos, que pueden situarse en el siglo XI. Curiosamente, en esta región son minoritarios los comportamientos funerarios rupestres. La comparación entre estas realidades y las otras áreas de la Beira donde las sepulturas excavadas en la roca son abundantes, están siendo objeto de estudio en el marco del proyecto "Estudo Interdisciplinar das Comunidades Alto Medievais. O caso de Viseu", financiado por la Fundación Calouste Gulbenkian y dirigido por la autora.
} 
sencia en superficie de fragmentos de cerámica común o de construcción -normalmente de cronología romana o tardo-romana- en las inmediaciones de las sepulturas, circunstancia documentada en los trabajos de diversos autores. Todos los investigadores portugueses que han trabajado este tema en el centro y norte del país han documentado, de alguna manera, esta situación. En el Alto Paiva, Marina A. Vieira (2004) recoge esta relación entre cerámica y sepulturas en 8 de los 32 yacimientos inventariados; en la cuenca del río Alva, Sandra Lourenço (2007) documentó la presencia de restos de cerámica común y/o de construcción en 53 de los 85 sitios presentados en su trabajo; para el área de Viseu, Jorge A. Marques también señala esta situación, y en la zona del Alto Duero portugués, I. Alexandra Lopes (2002) señala que, de los 72 sitios con sepulturas excavadas en la roca que identificó, en 30 había vestigios de cerámica romana/medieval en las inmediaciones, vinculándolos con los espacios de hábitat de aquéllos que usaron las sepulturas. También en la región de Riba Côa, Martín Viso (2008) documentó un patrón similar de asociación espacial de sepulturas rupestres con restos en superficie, tradicionalmente considerados como romanos. En la región del Alto Mondego, el 39,8 \% de los yacimientos con sepulturas está asociado a la presencia de cerámica común y de construcción, lo que reflejaría la presencia de una ocupación de tipo habitacional.

No obstante, la vinculación entre cerámica / materiales de construcción y sepulturas no es mayoritaria en ninguno de los trabajos señalados, lo que invalida la generalización de esta idea. Por otro lado, la asociación entre restos en superficie y sepulturas no es un vínculo suficiente para relacionarlos de manera inequívoca y directa. Es decir, porque existan algunos casos con presencia de tejas, ladrillos o cerámica común no se puede postular inmediatamente que son restos coetáneos a las evidencias funerarias. Sólo la realización sistemática de excavaciones en este tipo de sitios permitiría obtener datos suficientes para poder extraer conclusiones más seguras acerca de la relación entre sitios de hábitat y sepulturas excavadas en la roca. Sin dejar de tener en cuenta esta cautela, ya se están dando los primeros pasos en este sentido, pudiendo plantear algunas reflexiones al respecto.

El caso de S. Gens es paradigmático para este tipo de análisis espacial y de correlación con el poblamiento, dado que representa la mayor necrópolis desordenada del Alto Mondego y una de las mayores de toda la región de la Beira portuguesa. Señalábamos anteriormente cómo esta necrópolis está probablemente asociada a un asentamiento de carácter plurifamiliar (5 o 6 familias) concentrado en un poblado rodeado por una empalizada. Estas grupos explotarían los recursos forestales (caza y recolección) del entorno, a lo que se añadiría el pastoreo y, eventualmente, el cultivo de los campos junto al valle del Mondego (Tente, 2010). Por lo tanto, a pesar de expresar una organización familiar mediante la agrupación en núcleos de las sepulturas, esta necrópolis se asocia a un poblamiento pluri-familiar concentrado en un mismo espacio común. Se trata de una situación atípica, dado que los demás sitios contem- poráneos en el Alto Mondego (Penedo dos Mouros; Soida) que reflejan una ocupación relacionada con una comunidad no tienen ninguna necrópolis asociada. El yacimiento de Penedo dos Mouros tiene una única sepultura en la cima del tor que articula el espacio, mientras que Soida (Rapa, Celorico da Beira, cf. Tente, 2010: 267-314) no tiene ninguna sepultura en las inmediaciones que se pueda relacionar espacialmente con el asentamiento.

El túmulo de Penedo dos Mouros, como señalábamos anteriormente, parece representar simultáneamente la memoria (familiar o comunitaria) del espacio y su pérdida. Por este motivo no la consideramos contemporánea de la ocupación del emplazamiento. El espacio donde enterrarían a sus muertos los habitantes de Penedo dos Mouros es una cuestión que permanece aún por determinar. Dentro de la línea argumental de Iñaki Martín Viso (2012a, 2012b, 2014), puede plantearse que las sepulturas se encontrarían dispersas por los roquedos alrededor del poblado, o incluso en el fondo del valle del río Boco (controlado desde el yacimiento), garantizando así la delimitación y legitimación de la propiedad de la tierra por cada una de las familias que compartían el mismo poblado. Sin embargo, aún falta por confirmar que esta sea la realidad funeraria de este yacimiento.

El caso de Soida refleja una situación diferente. Este poblado, que también estaba cercado por una empalizada, se encuentra en altura, en un espacio que controla el acceso a las llanuras de la serranía, ricas en pasto. Los datos arqueológicos apuntan hacia una ocupación del sitio eventual, no permanente. Faltan algunos de los elementos que aparecen en S. Gens y en Penedo dos Mouros, como los útiles de molienda y de telar. Este yacimiento de montaña puede haber funcionado como complemento en el aprovechamiento de los recursos pastoriles sirviendo, parte del año, como espacio de apoyo y protección de quienes utilizaban los recursos de las llanuras serranas. Infelizmente los datos no permiten documentar de manera clara un movimiento vertical de trashumancia (no se conservan restos de fauna, ni documentación escrita que mencione este tipo de solución económica para el período medieval en esta región), pero podría tratarse de un modelo viable para explicar el emplazamiento y la actividad desarrollada en este yacimiento.

A pesar de estas consideraciones, las sepulturas siguen siendo un elemento guía para la búsqueda de poblados y espacios de hábitat altomedievales, dado que estos, construidos en su mayoría con materiales perecederos, dejan pocos rastros sobre el terreno. Y cuando la estrategia de prospección ha resultado provechosa en diferentes casos y zonas: por ejemplo en Castelo de Vide (Alto Alentejo), La Genestosa (Casillas de Flores) o Reguengos de Monsaraz (Alentejo Central), es en buena medida debido a la correlación directa de las sepulturas con los espacios de poblamiento. ¿De qué manera? ¿Cuáles son los patrones? Son preguntas todavía difíciles de responder, pero sin duda subyace la idea de que las sepulturas se construyen sólo en aquellos territorios utilizados y vividos por las gentes del espacio rural altomedieval. 


\section{4.- CONCLUSIONES}

El debate sobre el significado de la dispersión del mundo funerario rupestre altomedieval es y será siempre un debate abierto. Dado que, tal y como aquí se señaló para el territorio del Alto Mondego, las sepulturas excavadas en la roca tienen diferentes significados y expresan realidades socioeconómicas diversificadas, aunque no siempre las consigamos comprender por completo.

En una primera lectura las sepulturas son la morada de un difunto, pero socialmente asumen también otras funciones. Son memoria de los antepasados, sean recientes o más alejados. Son también los símbolos de la identidad familiar. Pero funcionan también como locales de la memoria colectiva, tal y como parece suceder en el caso de Penedo dos Mouros. Las sepulturas son, por encima de todo, elementos con un significado central en la vida de las comunidades rurales altomedievales. Es revelador que en el trabajo invertido en su construcción prime (de ahí que se elijan y excaven afloramientos rocosos) frente a lo que sucede con los lugares de habitación, mayoritariamente levantados con materiales perecederos. La durabilidad y la localización de los sepulcros es una cuestión deliberada. Aunque no consigamos comprender la totalidad de su significado, las sepulturas no pueden ser disociadas de la antropización y de la apropiación de los espacios rurales y forestales altomedievales. Su emplazamiento en valles, junto a caminos, en laderas y en alcores, en altiplanos serranos y en líneas de cumbre, ilustran la variabilidad de los espacios utilizados, vividos y aprovechados. Las sepulturas fueron, simultáneamente, los marcadores duraderos (casi eternos) y legitimadores de los espacios con significado propio para las gentes que en ellas se enterraban. La presencia de las sepulturas de los antepasados y de los familiares es reconocida como imbuida de un papel legitimador de explotación y/o posesión de un territorio en multitud de sociedades segmentarias. Un buen ejemplo de ello es el trabajo, ya clásico, de Renfrew acerca del megalitismo europeo (1976), en el que usó paralelos etnográficos para explicar el papel de los monumentos funerarios o de los espacios de enterramiento como marcadores territoriales.

La distribución de las sepulturas rupestres en el Alto Mondego ofrece la imagen de un espacio fragmentado, testimonio de realidades sociales segmentadas en comunidades locales donde la unidad familiar es la base nuclear de la sociedad. Sin embargo no resulta tan evidente su relación con un poblamiento también de carácter disperso. El caso de S. Gens apunta hacia una organización social de base familiar, en el que varias familias comparten el poblado, la necrópolis y, probablemente, los recursos de los alrededores. Pero este no es el patrón que encontramos en el Alto Mondego, donde la presencia dispersa de necrópolis desordenadas, de grupos pequeños y de sepulturas aisladas marca la tendencia. Todavía no es posible asegurar si este hecho se traduce también en un poblamiento rural disperso, pero lo que sí es cierto es que estas tumbas señalaban los espacios forestales y rurales aprovechados, de los que efectivamente se apropiaron.
Sólo la Iglesia consiguió romper con la lógica familiar y comunitaria expresada en estas manifestaciones funerarias altomedievales. Para ello hubo que esperar hasta la implantación del sistema parroquial, asociado a los procesos de repoblación y de reforma administrativa, social y económica, derivados del proceso de integración de esta región en la monarquía leonesa, primero, y portuguesa, a partir del siglo XII.

\section{5.- AGRADECIMIENTOS}

Lo trabajo está integrado en el proyecto de investigación HAR2010-21950-C03-02 "Territorios e identidades locales en el Centro de la Península Ibérica altomedieval: análisis especial de las tumbas excavadas en roca", dirigido por I. Martín Viso (Universidad de Salamanca, España). Parte de los resultados ya habían sido presentados y discutidos en el 2nd International Medieval Meeting de Lleida, celebrado entre el 26 y el 29 de junio de 2012. Así, por la discusión y los comentarios al texto, quería dar las gracias a Iñaki Martín Viso, a Marina Vieira, a Julio Escalona y a los evaluadores del texto. Por compartir datos y por el debate agradezco a Sara Prata, quien también colaboró en la traducción realizada por Fabián Cuesta. También quería agradecer a António Marques y a João Lobão por la información relativo a S. Gens. Por último, a mi marido, António Faustino Carvalho, cuya visión de arqueólogo prehistoriador me permite reflexionar y reinterpretar datos adquiridos hace ya tiempo.

\section{BIBLIOGRAFÍA}

ALARCÃO, J. de

1993 Arqueologia da Serra da Estrela. Parque Natural da Serra da Estrela. Manteigas.

ÁLVARO, K. \& PADILLA LAPUENTE, J. I.

2012 Arquitectura religiosa y necrópolis rupestres entre el alto Arlanza y la cabecera del Duero (ss. IX-XI). Hortus Artium Medievalium. 18(2), 445-458.

ANGELUCCI, D., TENTE, C. \& MARTINS, A. R.

2004 O Penedo dos Mouros e a sua integração paisagística. Revista Portuguesa de Arqueologia 7(1), 467-481.

\section{BARROCA, M. J.}

1987 Necrópoles e sepulturas medievais de Entre-Douro-eMinho (Séc. V a XV). Dissertação para Provas Públicas de Capacidade Científica, apresentada na FLUP. Porto (policopiado)

2010-11 Sepulturas escavadas na rocha de Entre Douro e Minho. Portugália, Nova Série 31-32, 115-182.

\section{BOLÓS i MASCLANS, J. y PAGÉS i PARRETAS, M.}

1982 Les sepultures excavades a la roca, en Acta Historica et Archaeologica Mediaevalia, 1: Annex Necrópolis i sepultures medievals de Catalunya 59-97. 
CHAPMAN, R. y RANDSBORG, K.

1981 Approaches to the archaeology of death, en CHAPMAN, R., KINNES, I. \& RANDSBORG, K. (eds.). The archaeology of death. 1-24. Cambridge University Press.

FERREIRA, F. E R.

2013 Arqueologia alto-medieval no regolfo do Alqueva. Vestígios de uma ocupação judaica nas margens do Guadiana no século VII. ẺDIA.

\section{FEREEIRA, T.}

1953 Velharias - Frutos das escavações na Cerca da Câmara. Jornal de Gouveia 21, 25 de Janeiro, 10.

LALIENA, C. y ORTEGA, J.

2005 Arqueología y poblamiento. La cuenca del río Martín en los siglos V-VIII. CEMA.

\section{LOBÃO, J., MARQUES, A. y TENTE, C.}

2013 S. Gens, Através da História e do Tempo. Celorico da Beira/Forno Telheiro.

\section{LOPES, I. A. R. J.}

2002 Contextos Materiais da Morte durante a Idade Média: as necrópoles do Douro Superior. Dissertação de mestrado em arqueologia apresentada à FLUP. Porto (policopiado).

\section{LOURENÇO, S.}

2007 O povoamento alto-medieval entre os rios Dão e Alva. IPA. Lisboa.

\section{MARQUES, J. A.}

2000 Sepulturas escavadas na rocha na região de Viseu. Viseu.

\section{MARQUES, A}

2011 A ocupação romana na Bacia de Celorico. Dissertação de mestrado em arqueologia apresentada à FLUC. Coimbra (policopiado).

\section{MARTIN VISO, I.}

2008 Una periferia creativa: la articulación del territorio en la comarca de Riba Côa (Portugal) (siglos VI-XI). Territorio, Sociedad y Poder 3, 85-109.

2011 La organización espacial de los espacios funerarios altomedievales en los territorios al Sur del Duero", en GOMES, R. V., GOMES, M. V. \& TENTE, C. (eds.). Cristãos e Muçulmanos na Idade média Peninsular: encontros e desencontros. 225-238. Lisboa.

2012a Enterramientos, memoria social y paisaje en la Alta edad Media: propuestas para un análisis de las tumbas excavadas en roca en el centro-Oeste de la Península Ibérica. Zephyrus LXIX, 165-187.

2012b Paisajes sagrados, paisajes eclesiásticos: de la necrópolis a la parroquia en el centro de la Península Ibérica. Reti Medievali Rivista 13(2), 3-45. Disponible en http://rivista.retimedievali.it

2014 El espacio del más acá: las geografías funerarias entre la Alta y la Plena Edad Media, en LÖPEZ OJEDA, E. (ed.) De la Tierra al Cielo. Ubi sunt qui ante nos in hoc mundo fuere? Actas de XXIV Semana de Estudios Medievales, Logroño. 75-140. Instituto de Estudios Riojanos.
MARTÍN VISO, I. y RUBIO DÍEZ, R.

2013 Informe técnico: primera campaña de excavación arqueológica en el yacimiento de La Genestosa (2012). Salamanca.

2014 Informe técnico: segunda campaña de excavación arqueológica en el yacimiento de La Genestosa (2013). Salamanca.

MARTÍN VISO, I. y BLANCO GONZÁLEZ, A.,

e.p. Ancestral memories and early medieval landscapes: the case of Sierra de Ávila (Spain). Early Medieval Europe (en prenta)

NETO, M. S.

2009 Celorico da Beira na época moderna, en MARQUES, A. C. y CARVALHO, P. C. (coords). Celorico da Beira, através da História. 93-107. Celorico da Beira.

NOGUEIRA, B. de Sá

2004 O espaço eclesiástico em território português (10961415), en AZEVEDO, C. M. (dir.). História Religiosa de Portugal Vol. 1. 142-201. Temas e Debates.

OLIVEIRA, E. V., GALHANO, F., \& PEREIRA, B.

1969 Construções Primitivas em Portugal. Edições Dom Quixote. Lisboa.

PANIAGUA VARA, E.

2012 Espacios funerarios y territorio en la Alta Edad Media: un análisis micro a partir del estudio de La Genestosa. (Casillas de Flores, Salamanca). Salamanca. Trabajo Fin de Máster (policopiado).

PEREIRA, T.

2013 Algodres (Fornos de Algodres), en Aspetos da Romanização das terras Beirãs de Entre Tejo e Douro. C. M. Celorico da Beira /ARA, 32.

RENFREW, C.

1976 Megaliths, territories and population, en DE LAET, S.J., (ed.). IV Atlantic Colloquim. Acculturation and continuity in Atlantic Europe mainly during the Neolithic period and the Bronze Age. 198-220. De Tempel.

\section{QUEIROZ, P.}

2009 Estudo antracológico no sítio de S. Gens, Celorico da Beira. (Terra Scenica -Território Antigo - Relatório 13) (policopiado).

QUEIROZ, P. y RUAS, J. P.

2001 Estudos de arqueobotânica no Penedo dos Mouros (Trabalhos do CIPA; 13) (policopiado).

RUBIO DÍEZ, R.

2011 Los sepulcros rupestres del suroeste salmantino. Mundo,funerario y poblamiento entre la tardoantigüedad y la Alta Edad Media. Salamanca. Trabajo de Grado (policopiado).

SILVA, A. R. P. y TELES, A. N.

1986 A Flora e a vegetação da Serra da Estrela. Manteigas. PNSE. 
SOARES, A. \& CARDOSO, $\mathrm{H}$.

2004 Algodres, Intervenção arqueológica de emergência. Relatório final (processo n. ${ }^{\circ}$ S-7640), (policopiado).

TENTE, C.

2000 Estudo sobre as sepulturas rupestres do actual concelho de Gouveia (1993-1998). Gaudela 1, 44-72.

2007 A ocupação alto-medieval da Encosta Noroeste da Serra da Estrela. Lisboa. IPA.

2010 Arqueologia Medieval Cristã no Alto Mondego, Ocupação e exploração do território nos séculos V a XI. Dissertação de doutoramento apresentada à UNL. Lisboa (policopiado).

\section{TENTE, C. \& CARVALHO, A. F.}

2011 The establishment of radiocarbon chronologies for early medieval sites: a case study from the upper Mondego Valley (Guarda, Portugal). Munibe Antroplogia-Arkeologia 62, 461-468.

\section{TENTE, C. \& LOURENÇO, S.}

1998 Sepulturas medievais escavadas na rocha dos concelhos de Carregal do Sal e Gouveia: estudo comparativo. Revista Portuguesa de Arqueologia 1(2), 191-217.

TENTE, C. \& MARTINS, A. C.

1994 Levantamento arqueológico do concelho de Gouveia, $1^{\mathrm{a}}$ fase: a necrópole medieval do Risado, o conjunto de Carreira Cova e a Sepultura do Penedo do Mouros. Notícia preliminar. Trabalhos de Arqueologia da E.A.M. 2, 283-291.
TENTE, C. \& PEREIRA, T.

2013 Monte Aljão (Rio Torto, Gouveia), en Aspetos da Romanização das terras Beirãs de Entre Tejo e Douro, C. M. 36. Celorico da Beira /ARA.

VALERA, A. C.

1990 Sepulturas escavadas na rocha do concelho de Fornos de Algodres. G.A.F.A.L.

VAN LEEUWAARDEN, W. \& QUEIRÓS, P.

2003 Estudos de arqueobotânica no Penedo dos Mouros /Gouveia - III. (Trabalhos do CIPA. 47) IPA (policopiado).

VENTURA, L. \& FARIA, A. S.

1990 Livro Santo de Santa Cruz (cartulário do séc. XII). Coimbra.

VIEIRA, M. A.

2004 Alto Paiva, povoamento nas épocas romana e alto-medieval. Lisboa. IPA.

2006 Alguns aspectos do povoamento Tardo Antigo e Alto Medieval do curso superior do rio Paiva. As sepulturas escavadas na rocha. Conimbriga XLV, 311-335. 